PONTIFÍCIa UNIVERSIDADE CATÓLICA DO RIO DE JANEIRO

\title{
Percepções e atitudes dos consumidores cariocas em relação aos serviços de reparação automotiva
}

\author{
Luan de Oliveira Antonio \\ Trabalho de Conclusão de Curso
}

CENTRO DE CIÊNCIAS SOCIAIS - CCS

DEPARTAMENTO DE ADMINISTRAÇÃO

Graduação em Administração de Empresas

Rio de Janeiro, junho de 2018. 
Luan de Oliveira Antonio

Percepções e atitudes dos consumidores cariocas em relação aos serviços de reparação automotiva

Trabalho de Conclusão de Curso

Trabalho de Conclusão de Curso, apresentado ao programa de graduação em Administração da PUC-Rio como requisito parcial para a obtenção do título de graduação em Administração.

Orientador: Daniel Kamlot

Rio de Janeiro

Junho de 2018 


\section{Agradecimentos}

Agradeço imensamente a minha família, que sempre me apoiaram a tudo e me indicaram o caminho correto de viver a vida. Agradeço aos meus amigos que, em momentos de tensão, sempre me ajudaram a aliviar-me do que me afligia e viver bons momentos. Agradeço a toda equipe da Localiza Hertz do aeroporto Santos Dumont que, independente de tudo, sempre me apoiaram e me ajudaram a tornar o presente estudo uma realidade. 


\section{Resumo}

Antonio, Luan de Oliveira. Percepções e atitudes dos consumidores cariocas em relação aos serviços de reparação automotiva. Rio de Janeiro, 2018. Número de páginas: 45. Trabalho de Conclusão de Curso Departamento de Administração. Pontifícia Universidade Católica do Rio de Janeiro. O presente estudo tem como objetivo averiguar a percepção e as atitudes dos consumidores cariocas em relação aos serviços prestados por oficinas mecânicas de automóveis independentes e especializadas. O estudo visa evidenciar as lacunas que as oficinas mecânicas possuem para que estas tenham uma melhoria no nível de serviço. A pesquisa do presente tem caráter quantitativa e os resultados foram obtidos através de questionários. Foi evidenciado um forte traço cultural do carioca a buscar uma solução de qualidade pelo menor preço. Portanto, é notório que o mercado da reparação automotiva possui amplas segmentos a serem explorados, públicos a serem melhor atendidos e aumentar a capacitação dos profissionais para acompanhar as tendências de mercado.

Palavras-chave: Reparação, Automotiva, Qualidade, Confiabilidade, Percepção, Atitude.

\section{Abstract}

Antonio, Luan de Oliveira. Percepções e atitudes dos consumidores cariocas em relação aos serviços de reparação automotiva. Rio de Janeiro, 2018. Número de páginas: 45. Trabalho de Conclusão de Curso Departamento de Administração. Pontifícia Universidade Católica do Rio de Janeiro.

The present study aims to investigate the perception and attitudes of consumers in Rio de Janeiro in relation to the services provided by independent and specialized auto mechanic workshops. The study aims to highlight the gaps that mechanical workshops have so that they have an improvement in the level of service. The present research has a quantitative character and the results were obtained through questionnaires. It was evidenced a strong cultural trait of the carioca to seek a solution of quality for the lowest price. Therefore, it is well known that the automotive repair market has large segments to be explored, public to be better served and to increase the professionals' capacity to follow market trends.

Key words: Repair, Automotive, Quality, Reliability, Perception, Attitude. 


\section{Sumário}

1. Introdução 1

1.1. - Objetivo Final 2

1.2. - Objetivos Intermediários 3

1.3. - Delimitação do Estudo 3

1.4. - Relevância do Estudo 3

2. Referencial Teórico 4

2.1. Serviços e suas Características 4

2.2. Diferenciação 6

2.3. Motivação

2.4. Percepção 8

2.5. Atitude 9

2.6. Cultura 11

3. Metodologia 14

3.1. Tipo de pesquisa 14

3.2. Universo e Amostra 14

3.3. Coleta de dados 15

3.4. Tratamentos de dados $\quad 15$

3.5. Limitações do método 16

4. Apresentação e análise dos resultados 17

4.1. Descrição dos resultados 17

4.2. Análise final dos resultados $\quad 28$

5. Considerações Finais 32

6. Referências Bibliográficas 34 


\section{Sumário de Gráficos}

Gráfico 1 - Crescimento do Volume de Reparos x Faturamento da Fábrica x Faturamento

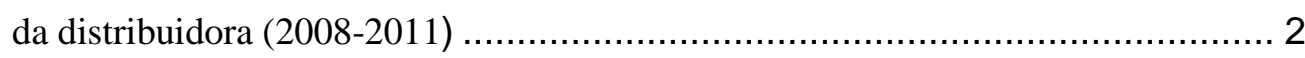

Gráfico 2 - Participação percentual do setor terciário (comércio e serviços) no valor

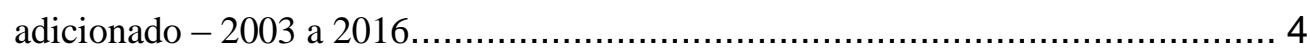

Gráfico 3 - Gênero da amostra............................................................... 17

Gráfico 4 - Média de renda da amostra ............................................................ 18

Gráfico 5 - Média de idade da amostra ...................................................... 18

Gráfico 6 - Grau de escolaridade............................................................. 19

Gráfico 7 - Área de residência ................................................................ 19

Gráfico 8 - Frequência de presença nas oficinas mecânicas ................................... 20

Gráfico 9 - Atributos que são diferencias na escolha de uma oficina.......................... 20

Gráfico 10 - Atributos que causam prejuízo na escolha de uma oficina ...................... 21

Gráfico 11 - Preferencia de escolha de oficinas.................................................... 23

Gráfico 12 - Opinião sobre o atendimento das oficinas ........................................ 24

Gráfico 13 - Opinião sobre qualificação das oficinas ............................................. 25

Gráfico 14 - NPS - Car Service com marca................................................. 26

Gráfico 15 - NPS - Car Service sem marca ................................................. 27

Gráfico 16 - NPS - Oficina pequeno porte ................................................... 27

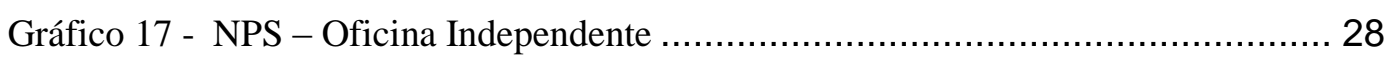




\section{Sumário de Figuras}

Figura 1 - Traçado do Circuito da Gávea ....................................................... 12

Figura 2 - Imagem da corrida na Avenida Niemeyer............................................ 13

Figura 3 - Car Service com marca (imagem ilustrativa) ......................................... 21

Figura 4 - Car Service sem marca ou de marca própria (imagem ilustrativa)................ 22

Figura 5 - Oficina de pequeno porte (imagem ilustrativa)................................... 22

Figura 6 - Oficina independente (imagem ilustrativa) ......................................... 23

\section{Sumário de Tabelas}

Tabela 1 - Principias motivos de escolha de oficina............................................ 24

Tabela 2 - Principais motivos de escolha - Atendimento ....................................... 24

Tabela 3 - Principais motivos de escolha - Qualificação............................................ 25

ANEXO I - $\quad$ Questionário elaborado pelo autor 


\section{Introdução}

O mercado de serviços de manutenção automotiva possui ampla variedade de redes autorizadas e oficinas independentes fornecendo diversos tipos de serviços, como: parte undercar (troca de componentes de suspensão, troca de pneus, alinhamento, balanceamento), parte de motores, funilaria, entre outros. Com o passar dos anos, a tecnologia chegou à indústria automotiva e, para acompanhar esse avanço, os serviços de mecânica tiveram que se adaptar e se modernizar para atender os novos veículos.

É notável a característica cultural do brasileiro de não exercer intervenções preventivas em seus veículos e recorrer a esses serviços apenas em momentos críticos. Ainda assim, proprietários de veículos se questionam sobre a capacidade de prestação de serviço e também em relação à honestidade dos profissionais do ramo, já que alguns se aproveitam da falta de conhecimento técnico dos proprietários para "levar vantagem" sobre eles. Em virtude do citado, o problema aqui identificado é a prática de desserviço prestado pelas oficinas mecânicas para os consumidores.

O mercado de reparação automotiva é um mercado que movimenta milhões de reais, porém, torna-se complicado precisar um valor, pois o mercado de reparação possui uma relação muito íntima com o mercado de venda de autopeças, visto que a demanda das mesmas, em sua maioria, é originada dentro do ambiente da oficina. Um estudo publicado pelo CINAU (2012) afirma que os serviços de reparação crescem de uma maneira menos acelerada em comparação ao crescimento de compras de carros novos, o que revela que a área de reparação automotiva é uma área que sofre pouco com crises econômicas. Conforme o Gráfico 1, numa análise de 4 anos (2008-2011), a quantidade de veículos cresceu $33 \%$, enquanto que a reparação cresceu apenas $26,8 \%$ (ambas taxas em âmbito nacional). 
Gráfico 1 - Crescimento do Volume de Reparos x Faturamento da Fábrica x Faturamento da distribuidora (2008-2011)

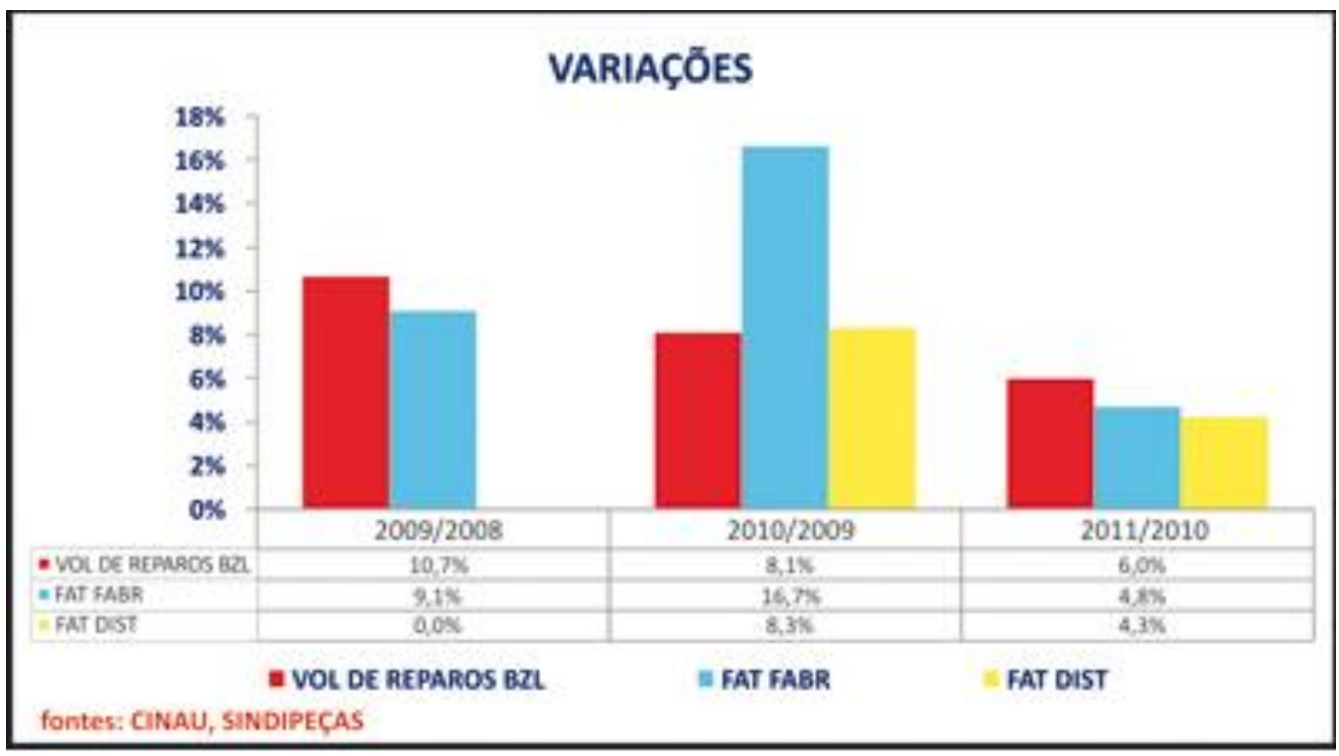

Fontes: CINAU (2012); SINDIPEÇAS (2012)

Com base nos dados informados e no problema identificado, o presente estudo possui o seguinte problema de pesquisa: Qual é a percepção e a atitude dos consumidores cariocas em relação aos serviços prestados por oficinas mecânicas independentes e especializadas?

\section{1.- Objetivo Final}

O objetivo final deste estudo é averiguar a percepção e as atitudes dos consumidores cariocas em relação aos serviços prestados por oficinas mecânicas de automóveis independentes e especializadas. As oficinas especializadas podem ser classificadas como oficinas que atendem somente uma montadora de veículos e/ou multimarcas, geralmente bem equipadas e com uma quantidade de profissionais grande. As oficinas independentes são conhecidas por serem mais discretas, com pouco espaço para atendimento e, geralmente, menos equipadas e com menor quantidade de profissionais, quando comparadas às oficinas especializadas. 


\section{2.- Objetivos Intermediários}

- Analisar a atitude dos consumidores em relação aos dois tipos de oficinas estudadas

- Averiguar a percepção de capacitação dos profissionais do ramo pelos consumidores

- Verificar a percepção da honestidade dos profissionais pelos consumidores

- Verificar a percepção do nível de serviço geral pelos consumidores

\section{3.- Delimitação do Estudo}

O estudo está limitado aos consumidores pessoas físicas, de ambos os sexos e maiores de idade, dos serviços de oficinas mecânicas especializadas e independentes no que tange à reparação de itens undercar e no reparo de motores da região metropolitana do Rio de Janeiro. A pesquisa foi delimitada no intuito de abranger a grande massa que circula pelas principais regiões da capital carioca.

\section{4.- Relevância do Estudo}

O estudo possui relevância para todos os consumidores das regiões delimitadas para o estudo pois evidencia as qualidades e os defeitos da prestação dos serviços identificados pelos consumidores, para as oficinas de todos os tipos, uma vez que mostra o feedback dos consumidores em relação a diversos aspectos das empresas como nível de serviço, apresentação da empresa e a apresentação, qualificação e honestidade dos profissionais.

Além disso, o estudo possui relevância para a academia, pois o mesmo utilizase de teorias elaboradas para identificar aspectos deste mercado que possui um grande potencial, mas é pouco explorado em termos acadêmicos, fornecendo, assim, subsídios para futuros estudos neste mercado. Por haver pouco material publicado sobre esse assunto na literatura de gestão e administração, o presente trabalho se mostra relevante, por poder contribuir como referência para pesquisas futuras. 


\section{Referencial Teórico}

A seguir, com o intuito de situar o leitor sobre os conceitos técnicos abordados no estudo, será evidenciada a base teórica que irá fundamentar a elaboração da pesquisa.

\subsection{Serviços e suas Características}

Serviço pode ser definido como qualquer ato, necessariamente intangível, que uma parte oferece à outra e que não resulta em propriedade (KOTLER e KELLER, 2006). O setor de serviços é um dos mais importantes da economia em diversas nações do mundo e, no Brasil, é o setor que possui uma relevância considerável na economia brasileira, mas passa por quedas no setor devido à crise econômica vivida no país.

Segundo os dados das Contas Nacionais Trimestrais do Instituto Brasileiro de Geografia e Estatística (IBGE, 2017), divulgados no site do Ministério da Indústria, Comércio Exterior e Serviços, de 2003 a 2016, a representatividade do setor terciário (que abrange as atividades de comércio de bens e prestação de serviços) passou de $65,8 \%$ para $73,3 \%$ do valor adicionado ao Produto Interno Bruto (PIB) brasileiro. É possível observar tal participação no Gráfico 2:

Gráfico 2 - Participação percentual do setor terciário (comércio e serviços) no valor adicionado - 2003 a 2016

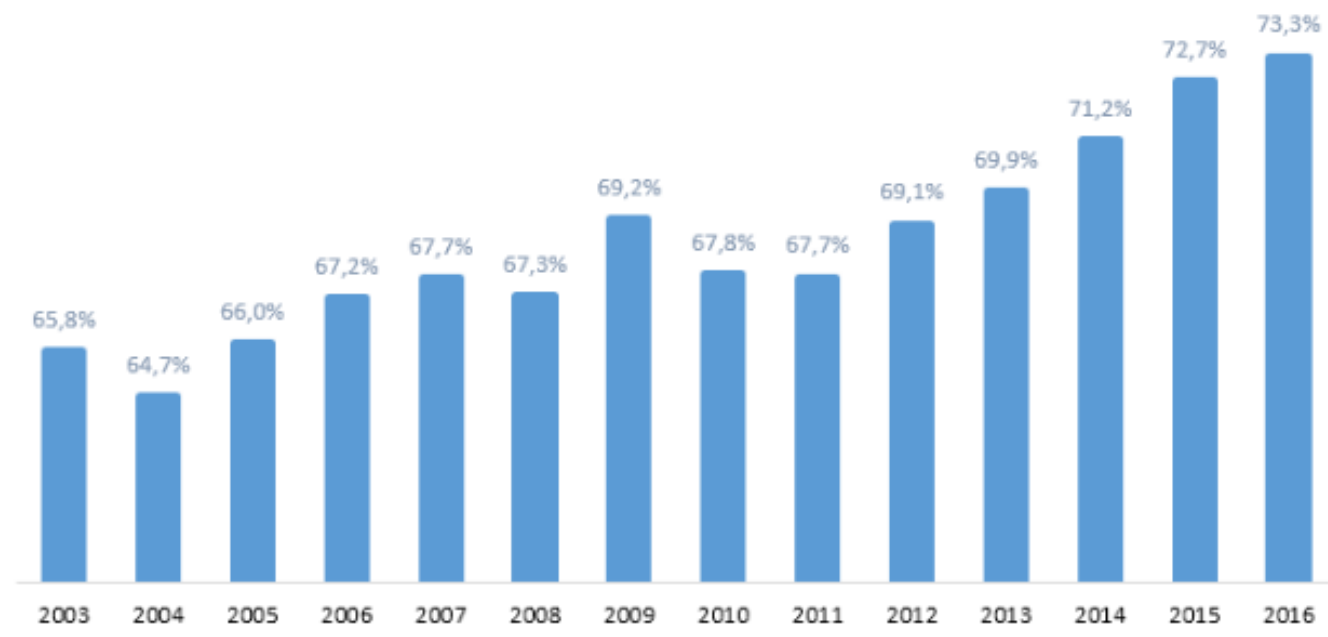

Serviços (comércio incluido)

Fonte: Contas Nacionais Trimestrais/IBGE. Elaboração: CGMD/SDS/MDIC (2017) 
O setor de serviços, por si só, teve um aumento na representatividade de 53,3\% em 2003 para 60,8\% em 2016 (IBGE, 2017).

O serviço de reparação automotiva possui diversas subcategorias como a parte undercar (troca de componentes de suspensão, troca de pneus, alinhamento, balanceamento), a categoria de reparo de motores, parte de funilaria e pintura, reparos da parte elétrica (módulos de ignição, injeção eletrônica), entre outros. A partir destas definições, é possível determinar algumas características relativas à prestação de serviços de reparação automotiva:

1. Intangibilidade - Os serviços de reparação, assim como todos os outros, não estão sujeitos às experiências sensíveis (audição, tato, olfato, visão e paladar) prévias, como peças automotivas estão, por exemplo.

2. Inseparabilidade - A execução e o consumo dos serviços de reparação podem ser executados e consumidos simultaneamente ou não. Como no caso de um proprietário deixar seu veículo em uma oficina e buscar quando a execução do serviço for concluída ou acompanhar a execução simultaneamente.

3. Variabilidade - $\mathrm{O}$ serviço de reparação varia de acordo com o modelo do veículo a ser reparado e, em alguns casos, o cenário de reparação pode variar de acordo com o diagnóstico (trocar mais peças do que o orçado).

4. Perecibilidade - A reparação automotiva pode ser preventiva ou corretiva, mas uma característica fundamental é que esta deve ser realizada em períodos específicos ao longo do uso do veículo de acordo com o manual do fabricante e, caso o serviço não seja realizado no período correto, o proprietário do veículo pode sofrer com danos causados pelo desgaste dos componentes. 
Segundo Grönroos (2004, p.36), "serviço é uma atividade ou uma série de atividades de natureza mais ou menos intangível que é fornecida como solução aos problemas dos clientes", assim, é imprescindível que a prestação de serviços tenha excelência para proporcionar a resolução do problema para o cliente, assim, no mercado de reparação automotiva, a confiabilidade do serviço e a credibilidade da marca estão diretamente relacionadas à esta excelência.

\subsection{Diferenciação}

A diferenciação no mercado de serviços de reparação automotiva, de maneira geral, é difícil de ser percebida pelo consumidor final pois, em sua grande parte, estes possuem uma metodologia padronizada de execução seguidas pela grande maioria do mercado. Tendo em vista a afirmação anterior, podemos estabelecer alguns pontos de paridade que, segundo Kotler e Keller (2006, p. 307) "são associações não necessariamente exclusivas à marca e que assumem duas formas básicas":

1. Paridade de categoria: Associações percebidas pelos consumidores como diferenciais para que a prestação de serviços seja confiável.

2. Paridade de concorrência: Associações que promovem diferenciações entre os concorrentes.

A partir da definição acima, é possível identificar que os pontos de paridade de categoria no serviço de reparação automotiva são: Equipamentos e instalações (ferramentas, elevadores, estrutura física) e pessoal qualificado. Por sua vez, os pontos de paridade de concorrência são: Maior gama de serviços, marca (própria ou franquia), atendimento e inovação.

A fim de obter vantagens no mercado, os competidores visam obter pontos de diferença entre si para que os clientes associem a qualidade e os benefícios da prestação de serviços à marca da sua oficina (KOTLER e KELLER, 2006). Diversas empresas no ramo da reparação automotiva buscam inovar, não somente na metodologia de execução dos serviços, mas também na aquisição de 
equipamentos e aprimoramento de instalações e na mão de obra, a fim de oferecer recursos inovadores durante a prestação de serviços. Com relação às oficinas mecânicas, alguns diferenciais que são oferecidos no mercado são o atendimento diferenciado e a experiência na oficina (com a criação de ambientes de convivência para consumidores enquanto o serviço é executado). Uma vez que estes diferenciais são apresentados ao cliente, aliados à qualidade da reparação do veículo, os clientes tendem a fidelizar as revisões do seu carro à oficina e a realizar o chamado marketing boca a boca, indicando a mesma para terceiros, assim fortalecendo a marca do estabelecimento e promovendo-a de forma gratuita.

\subsection{Motivação}

Para adquirir serviços prestados pelas oficinas, assim como outros tipos de serviços, é preciso estar motivado a isso e, neste aspecto, é possível identificar um forte traço cultural carioca de somente motivar-se a adquirir o serviço de reparação quando o veículo já se encontra em pane e não de forma preventiva. Segundo Kotler e Keller (2006, p. 183) “o motivo é uma necessidade que é suficientemente importante para levar uma pessoa a agir".

Inúmeros autores de diversas áreas estudam o impacto da motivação em indivíduos, porém o presente estudo visa focar em uma teoria motivacional específica, que é a teoria dos dois fatores de Frederick Herzberg. A teoria dos dois fatores tem como objetivo principal identificar os fatores que causavam insatisfação e satisfação dentro do ambiente de trabalho (PERIARD, 2011), porém, essa teoria também pode ser usada para o público consumidor.

Essa teoria é baseada em fatores higiênicos (que causam insatisfação) e fatores motivacionais (fatores que causam satisfação). Tendo em vista que a ausência de fatores higiênicos não é suficiente para que haja a aquisição do serviço, os fatores motivacionais devem existir para motivar a compra (KOTLER e KELLER, 2006, p. 184). No mercado de serviços, existe uma procura constante dos vendedores para minimizar a existência de fatores higiênicos e maximizar a presença de fatores motivacionais para que o consumidor compre mais, uma vez que, com as constantes mudanças na sociedade, os fatores que motivam o consumo também se modificam constantemente e, com base nas asserções feitas 
anteriormente, serão analisados no presente estudo quais fatores motivam ou não os consumidores cariocas a consumir os serviços de reparação.

\subsection{Percepção}

A partir da motivação dos consumidores, este trabalho irá abordar outro ponto chave para o estudo: a percepção. A percepção pode ser definida como o processo no qual as sensações humanas são selecionadas, organizadas e interpretadas (SOLOMON, 2008). Cada indivíduo possui uma determinada percepção sobre um produto e/ou serviço, sendo assim, a percepção influencia o comportamento de consumo.

A partir desta definição, a pesquisa irá abordar a percepção dos consumidores em relação aos serviços prestados e profissionais das redes de oficinas especializadas e independentes com base em dois aspectos da teoria: a atenção seletiva e a distorção seletiva (KOTLER e KELLER, 2006 p.184), cujas definições estão apresentadas a seguir:

1. Atenção seletiva consiste nos estímulos que despertam ou têm alguma relação com alguma necessidade consumidores e que eles absorvem com mais facilidade.

2. Distorção seletiva consiste na tendência em que os consumidores transformam uma informação, baseando-se em significados e experiências pessoais.

A percepção do consumidor é um importante fator sobre o seu processo de compra, pois a mesma consiste da compreensão que o indivíduo possui do ambiente ao seu redor sendo identificado pelos cinco sentidos humanos: o paladar, o olfato, a audição, a visão e o tato (SCHIFFMAN e KANUK, 2000) e, aliando-se aos fatores que motivam a compra, obtemos o comportamento de consumo dos clientes das oficinas de reparação.

Tendo em vista tais definições, será possível identificar a percepção dos consumidores cariocas sobre a qualidade e a confiabilidade dos serviços de reparação automotiva. 


\subsection{Atitude}

Outro aspecto importante na decisão de consumo são as atitudes dos consumidores. Atitudes são orientações aprendidas a fim de conceder uma resposta a um objeto ou a uma classe de objetos de forma favorável ou desfavorável (SHETH, MITTAL e NEWMAN, 2001). A formação de uma atitude consiste em três pilares centrais: crenças, afeto e intenções de comportamento. $\mathrm{O}$ processo de formação das atitudes consiste da formação de crenças do consumidor com relação a um produto e/ou serviço, sendo que, em seguida, o indivíduo realiza alguma avaliação do produto e/ou serviço, gerando ou não afeto para com o mesmo e então toma uma ação (comportamento) (SILVA, 2018).

Após estas definições, conclui-se que a atitude é formada por experiências prévias e/ou informações sobre um determinado produto e/ou serviço e isto, aliado aos fatores motivacionais e das percepções dos consumidores, gera um comportamento de compra.

As atitudes, segundo o modelo de Kotz, são divididas em 4 funções (SOLOMON, 2008):

1. Funções utilitárias: Atitudes tomadas em função das sensações, como a sensação de desconfiança do diagnóstico do profissional de reparação por exemplo;

2. Funções expressivas de valor: Atitudes tomadas com base no autoconceito ou nos valores do indivíduo, como a determinação, por parte do consumidor, da troca de uma peça especifica, ou ainda de diagnóstico, em uma parte específica do veículo, por parte do proprietário;

3. Funções defensivas do ego: Atitudes que ocorrem a fim de promover a autoproteção do indivíduo de ameaças internas ou externas como a recusa de um diagnóstico por parte do proprietário; 
4. Funções do conhecimento: Atitudes em que o indivíduo tem como objetivo buscar um significado sobre algo desconhecido, como o acompanhamento dos serviços de reparo feito no veículo para obter conhecimento sobre seu automóvel.

Os três pilares centrais de formação das atitudes podem ser formados por meio das hierarquias de efeito, que podem ser implementadas de acordo com o tipo de processo de compra (SILVA, 2018). São elas:

1. Hierarquia de Aprendizagem-padrão: Consiste da vivência de uma decisão de compra como um processo de solução de um problema. O consumidor adquire informações sobre atributos (crenças) relevantes sobre o produto e/ou serviço e desenvolve um sentimento (afeto) sobre o mesmo e, finalmente, assume o comportamento de comprar ou não o produto.

2. Hierarquia de Baixo Envolvimento: Consiste na existência de um baixo envolvimento no processo de compra e isso gera a adoção de uma solução limitada para o problema.

3. Hierarquia Experiencial: Consiste na forte influência dos sentimentos no processo de compra. Os atributos intangíveis do produto, como o design da embalagem por exemplo, podem provocar emoções no consumidor. As compras por impulso são um exemplo da hierarquia experiencial.

Em virtude disto, analisar esse ponto aliado aos tópicos anteriores é importante para entender fatores que levam os consumidores a terem uma atitude positiva ou uma atitude negativa para com os prestadores de serviços de reparação automotiva. A identificação e a comunicação do profissional para o cliente de um reparo a ser feito antes do período de revisão é um exemplo de atitude do profissional que, aliada à percepção do consumidor e a motivação geram uma atitude positiva para o consumo e, posteriormente, de indicação dos serviços. Por exemplo, a troca de um componente do veículo do cliente em perfeito estado de funcionamento sem a necessidade acaba acarretando uma atitude negativa do 
cliente e isto afeta negativamente a relação do profissional para com o mesmo, reduzindo a confiabilidade destes tipos de serviços.

\subsection{Cultura}

A cultura pode ser definida como a personalidade de uma sociedade em que os valores e crenças culturais da mesma têm influência direta no comportamento de consumo dos cidadãos (SOLOMON, 2008). Os fatores culturais são subdivididos em três: cultura, subcultura e classe social.

a. Cultura: Segundo Santos (1994, p. 7), "cultura diz respeito às maneiras de conceber e organizar a vida social e seus aspectos materiais, o modo de produzir para garantir a sobrevivência e o modo de ver o mundo".

b. Subcultura: Segundo Kotler (1998, p. 162), “cada cultura consiste em subculturas menores, as quais fornecem identificação mais específica e socialização para seus membros”. Dentro do âmbito das subculturas estão incluídos as nacionalidades, religiões, grupos raciais e regiões geográficas.

c. Classe Social: Segundo Kotler (1998, p. 163), “classes sociais são divisões relativamente homogêneas e duradouras de uma sociedade, que são ordenadas hierarquicamente e cujos membros compartilham valores, interesses e comportamentos similares".

Em uma linha histórica, a cultura carioca possuía um grande evento automobilístico de proporções internacionais denominado o Circuito da Gávea, que ocorreu entre os anos de 1933 e 1954 com um intervalo entre os anos de 1942 a 1946 devido à Segunda Grande Guerra (ELIAS e MOURÃO, 2010). O circuito chegava a atrair 250 mil espectadores para assistir aos carros velozes e pilotos corajosos correndo pelas ruas dos bairros da Gávea e do Leblon, zona sul do Rio de Janeiro (DELAMARE; TEIXEIRA; MAIA, 2005). A partir da década de 1950 o automobilismo perde influência no Rio de Janeiro com a morte de Getúlio 
Vargas, que possuía muita influência na realização da prova no país, pelas mudanças urbanas que ocorriam na cidade e em 1956 houve a implantação da indústria automobilística em São Paulo, fortalecendo o estado vizinho (ELIAS e MOURÃO, 2010).

Após estes anos, foram feitas inúmeras tentativas de promover corridas em circuitos urbanos nas regiões do Castelo, Praia de Botafogo e do Maracanã, entretanto as condições eram inadequadas para realizações de eventos por serem áreas muito povoadas e com condições ruins das vias. Até a construção do autódromo do Rio de Janeiro, a cena automobilística ficou esquecida na cultura carioca, sendo vivida apenas por alguns jovens da Zona Sul que organizavam corridas clandestinas na região, mas que também foram suprimidas pelo poder público (ELIAS e MOURÃO, 2010).

Figura 1 - Traçado do Circuito da Gávea

\section{Circuito da Gávea, ontem e hoje}

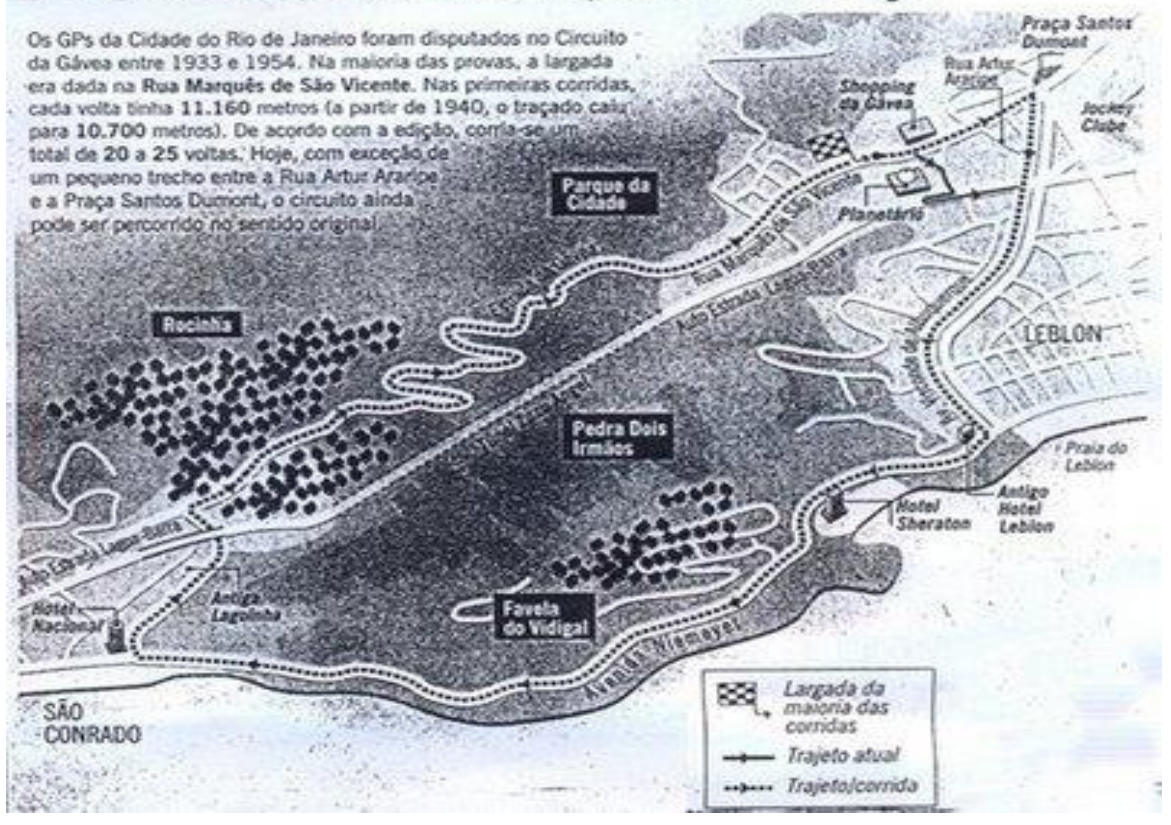

Fonte: historiadoesporte.wordpress.com (2013) 
Figura 2 - Imagem da corrida na Avenida Niemeyer.

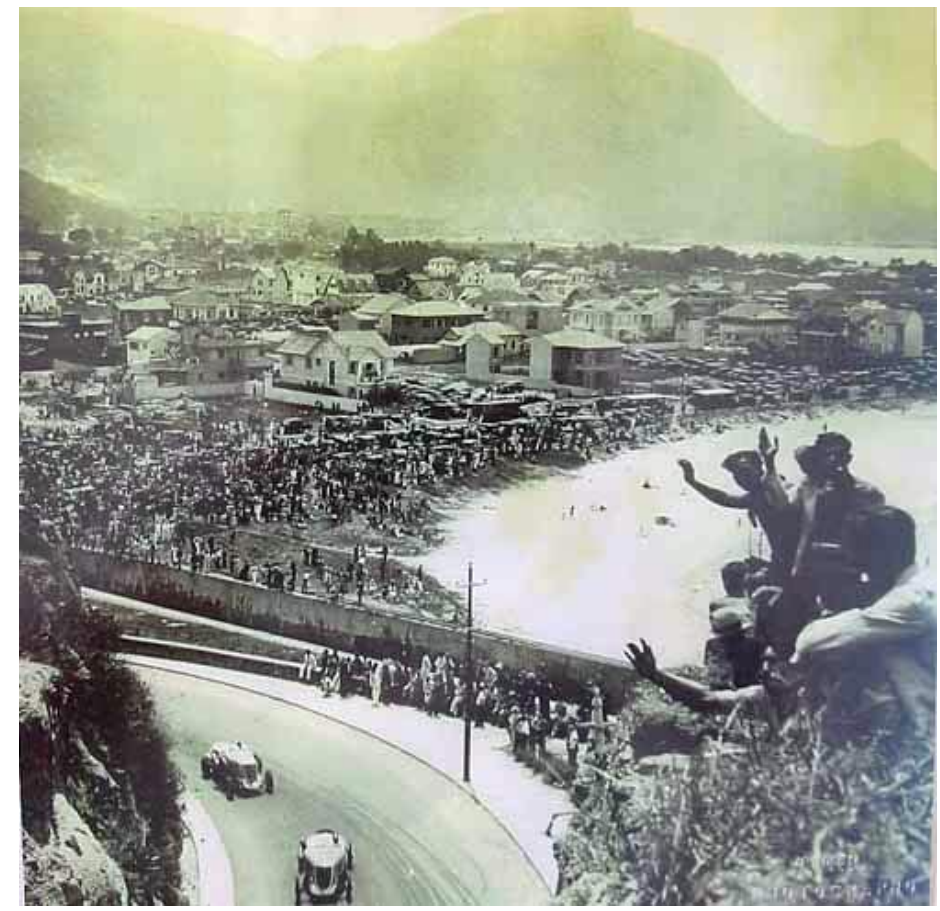

Fonte: historiadoesporte.wordpress.com (2013) 


\section{Metodologia}

\subsection{Tipo de pesquisa}

A realização da pesquisa se justifica pelo interesse em descrever quais são os principais motivos que levam o consumidor a escolher uma determinada oficina mecânica e a consumir os serviços de reparação. Para este fim, serão utilizados dois itens do referencial teórico que pautarão a elaboração do instrumento de coleta de dados para a pesquisa:

1. Qual a motivação que os consumidores possuem para ir à uma oficina mecânica?

2. O que faz os consumidores terem uma preferência entre oficinas mecânicas concorrentes? Qual a percepção dos consumidores em relação à qualidade e à confiabilidade dos serviços?

A pesquisa tem caráter descritivo com natureza exploratória, que não permitem alcançar conclusões definitivas (BABBIE, 1998; CRESWELL, 2003; RICHARDSON, 1999, apud CAMARGO e KEISER, 2008, p. 7).

\subsection{Universo e Amostra}

A população da pesquisa é composta por pessoas físicas que possuem automóveis, que consomem serviços de reparação automotiva e que residem na região metropolitana do Rio de Janeiro. A amostra utilizada foi não probabilística, que tem como sua definição ser uma amostra cuja escolha dos elementos é feita de forma não-aleatória, adotando critérios de escolha intencionais ou por conveniência, considerando as características particulares do grupo em estudo ou o conhecimento do pesquisador sobre o que se está investigando (GIL, 1987; RICHARDSON, 1999).

O critério de amostra adotado para a pesquisa é a amostragem não probabilística por conveniência, na qual o pesquisador seleciona membros da população mais acessíveis para a otimização de custo e tempo (SCHIFFMAN e KANUK, 2000). O tamanho da amostra final foi de 98 participantes a fim de garantir um percentual de margem de erro abaixo de $10 \%$. 


\subsection{Coleta de dados}

O presente estudo utilizou-se da estratégia de levantamento e coleta de dados através de instrumento pré-definido (questionário), que consiste em uma técnica de investigação composta por um número elevado de questões apresentada ao público e que fornece uma descrição numérica de tendências, atitudes e/ou opiniões da população por meio de uma amostra e permite análises estatísticas dos dados obtidos (CRESWELL, 2003, p. 161; GIL, 1999, p.128).

O questionário foi elaborado com perguntas objetivas, subjetivas de respostas curtas e com indicadores avaliando o grau de indicação de determinados tipos de oficinas de reparação em uma escala adaptada de Likert, de 10 pontos (variando de não recomenda até recomenda). Além dos indicadores sobre a percepção de qualidade e confiabilidade dos serviços de reparação automotiva, também foram utilizadas questões para identificação de características do respondente (sexo, idade, renda, grau de escolaridade e região onde reside).

Foram aplicados 119 questionários fechados divulgados por meio das redes sociais. Dentre estes, 21 foram descartados por apresentar inconsistências em algumas questões. Assim, a amostra final foi restringida a 98 questionários válidos.

\subsection{Tratamentos de dados}

A abordagem adotada para o presente estudo foi a quantitativa, que se centra na objetividade e, devido às amostras serem geralmente grandes e consideradas representativas da população, os resultados podem ser interpretados como um retrato real de todo o público alvo da pesquisa (FONSECA, 2002, p.20).

O processo de análise dos dados se deu por duas etapas:

1. Foi realizado um filtro nas respostas sobre as características dos respondentes a fim de garantir a delimitação do estudo (maiores de idade, residentes da região metropolitana do Rio de Janeiro e detentores de automóvel), gerando assim respostas válidas para o estudo. 
2. Os dados quantitativos, coletados por meio dos questionários, foram processados pela ferramenta de pesquisa "formulários Google" e apresentados e analisados utilizando-se do método da estatística descritiva, que visa obter informações úteis através de um conjunto de dados de forma a proporcionar uma resolução de um problema ou evidenciar resultados obtidos por meio de tabelas e gráficos.

\subsection{Limitações do método}

$\mathrm{Na}$ pesquisa, as unidades de análise envolvidas foram escolhidas adotando-se o critério de conveniência, em função do grande número de respondentes e otimização de tempo. Amostras por conveniência podem ser justificadas em um estágio exploratório da pesquisa, como uma base para geração de hipóteses (KINNEAR e TAYLOR, p. 187; CHURCHILL, p. 301). Portanto, os resultados não poderão ser considerados conclusivos.

Outra limitação presente no método é o possível viés de resposta positiva com relação a um determinado tipo de oficina e negativa para com outros modelos de negócio em caso de os respondentes levarem em consideração o afeto criado a um tipo de oficina já preferida e renegar a excelência na prestação de serviços de outras oficinas. 


\section{Apresentação e análise dos resultados}

Este item está organizado em duas seções, apresenta e discute os principais resultados alcançados, analisa e discute suas implicações e produz sugestões sobre o estudo.

\subsection{Descrição dos resultados}

Através da análise descritiva feita com os dados obtidos nos questionários respondidos, busca-se averiguar 3 questões relativas ao propósito do estudo. São eles:

Questão 1: Quais são as características demográficas da amostra?

Os aspectos demográficos da amostra são resultados importantes para a pesquisa pois os mesmos têm forte influência nos fatores de consumo que formam a motivação, atitudes e nas percepções dos consumidores. Foram obtidos dados relativos ao gênero, renda, idade, grau de escolaridade e bairro onde residem e os resultados são evidenciados nos gráficos a seguir:

Gráfico 3 - Gênero da amostra

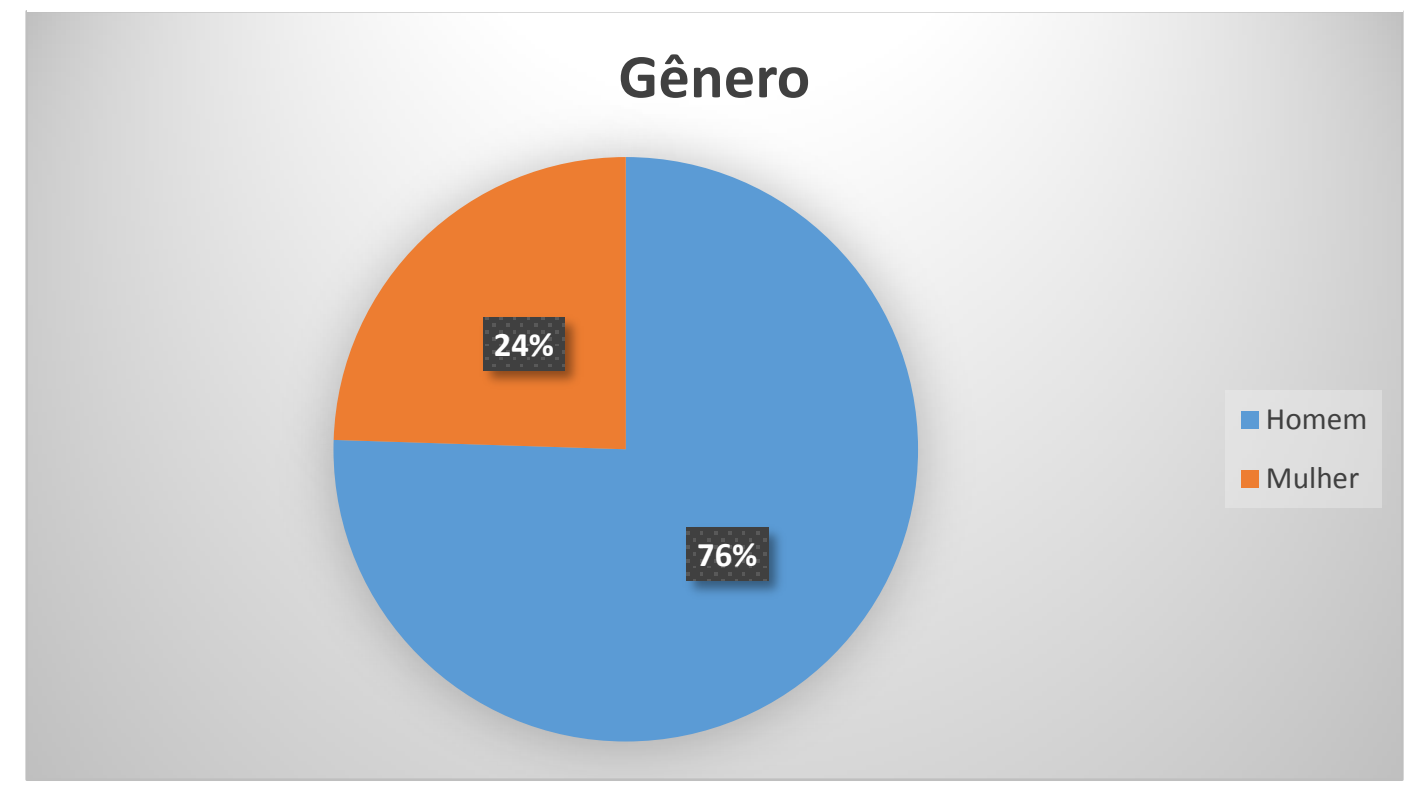

Fonte: Elaborado pelo autor a partir da ferramenta "Google Forms" 
Gráfico 4 - Média de renda da amostra

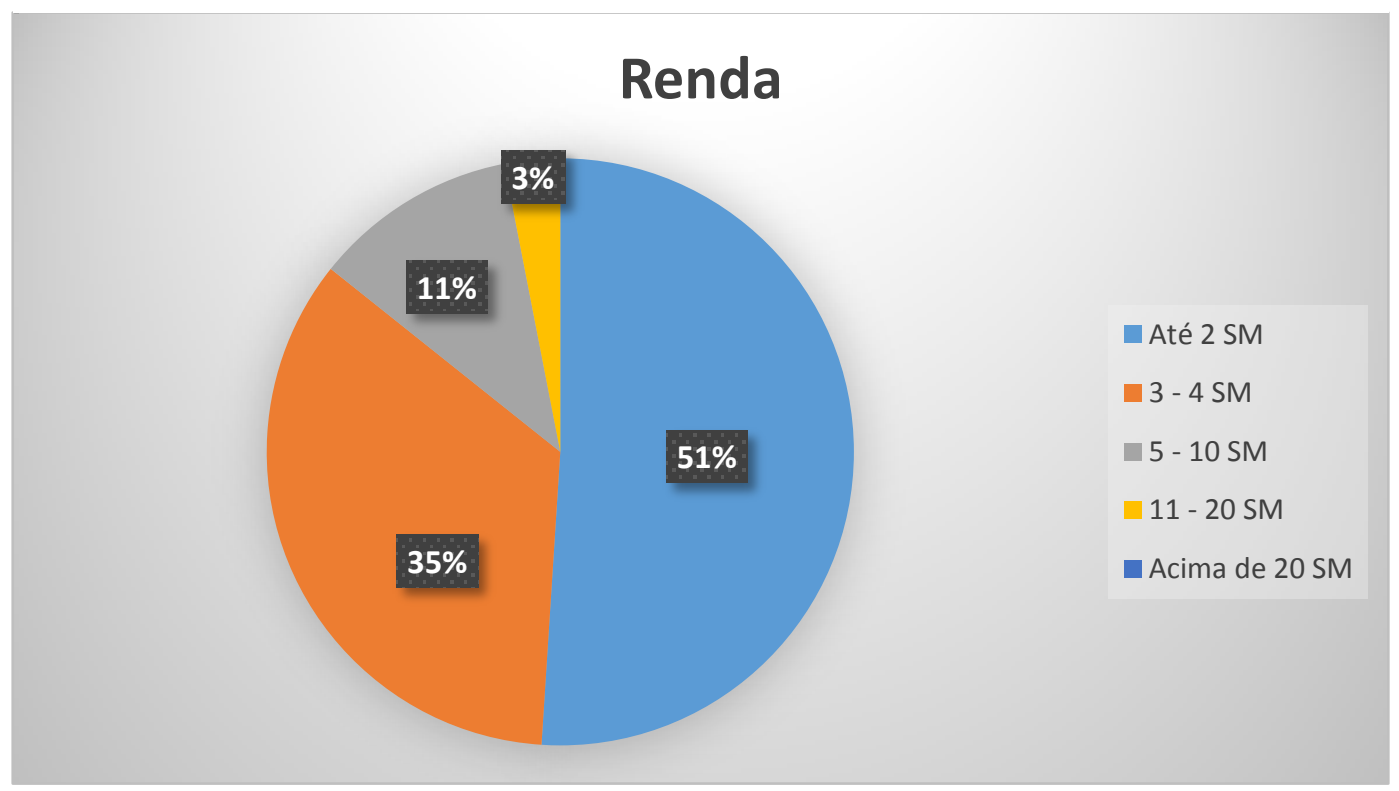

Fonte: Elaborado pelo autor a partir da ferramenta "Google Forms"

Gráfico 5 - Média de idade da amostra

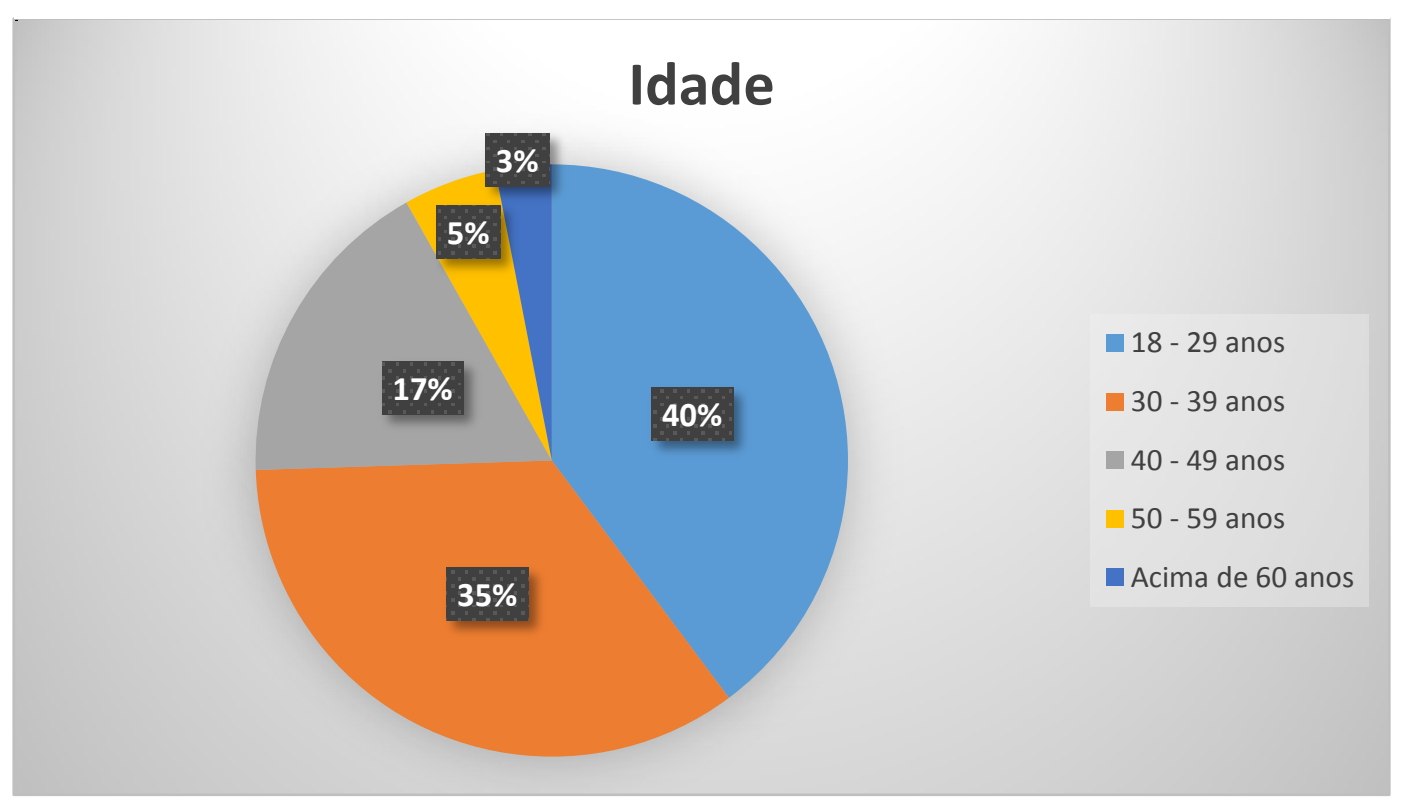

Fonte: Elaborado pelo autor a partir da ferramenta "Google Forms" 
Gráfico 6 - Grau de escolaridade

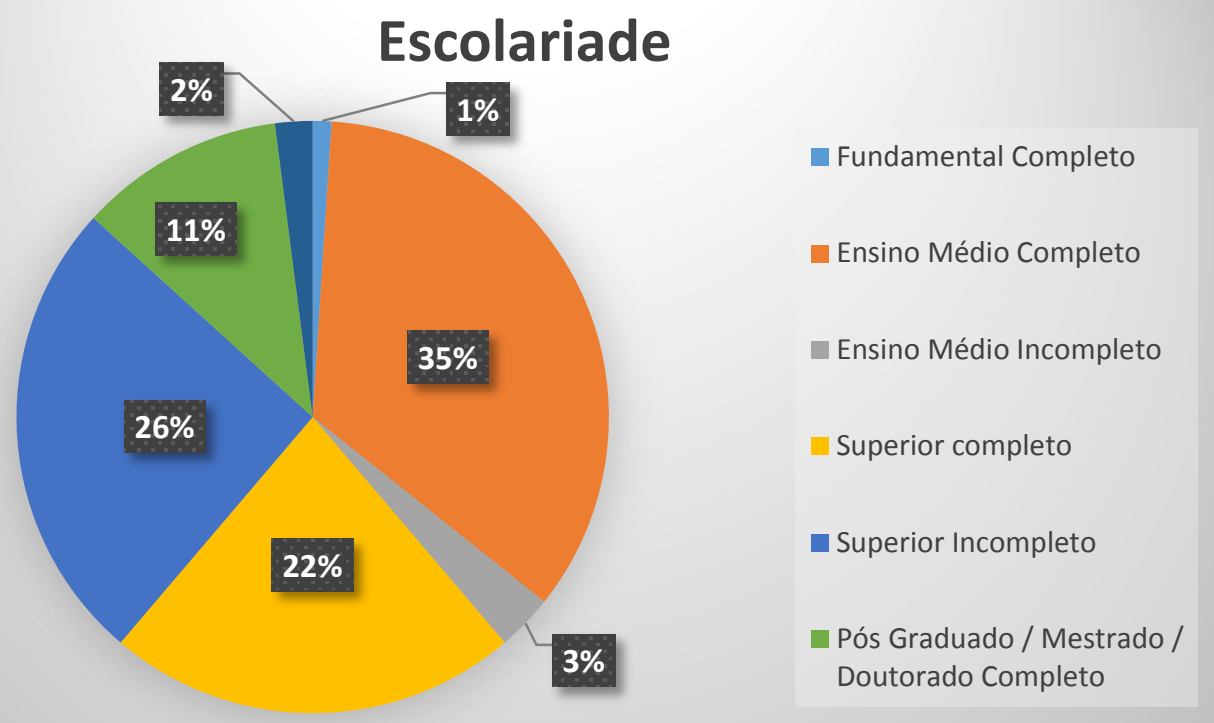

Fonte: Elaborado pelo autor a partir da ferramenta "Google Forms"

Gráfico 7 - Área de residência

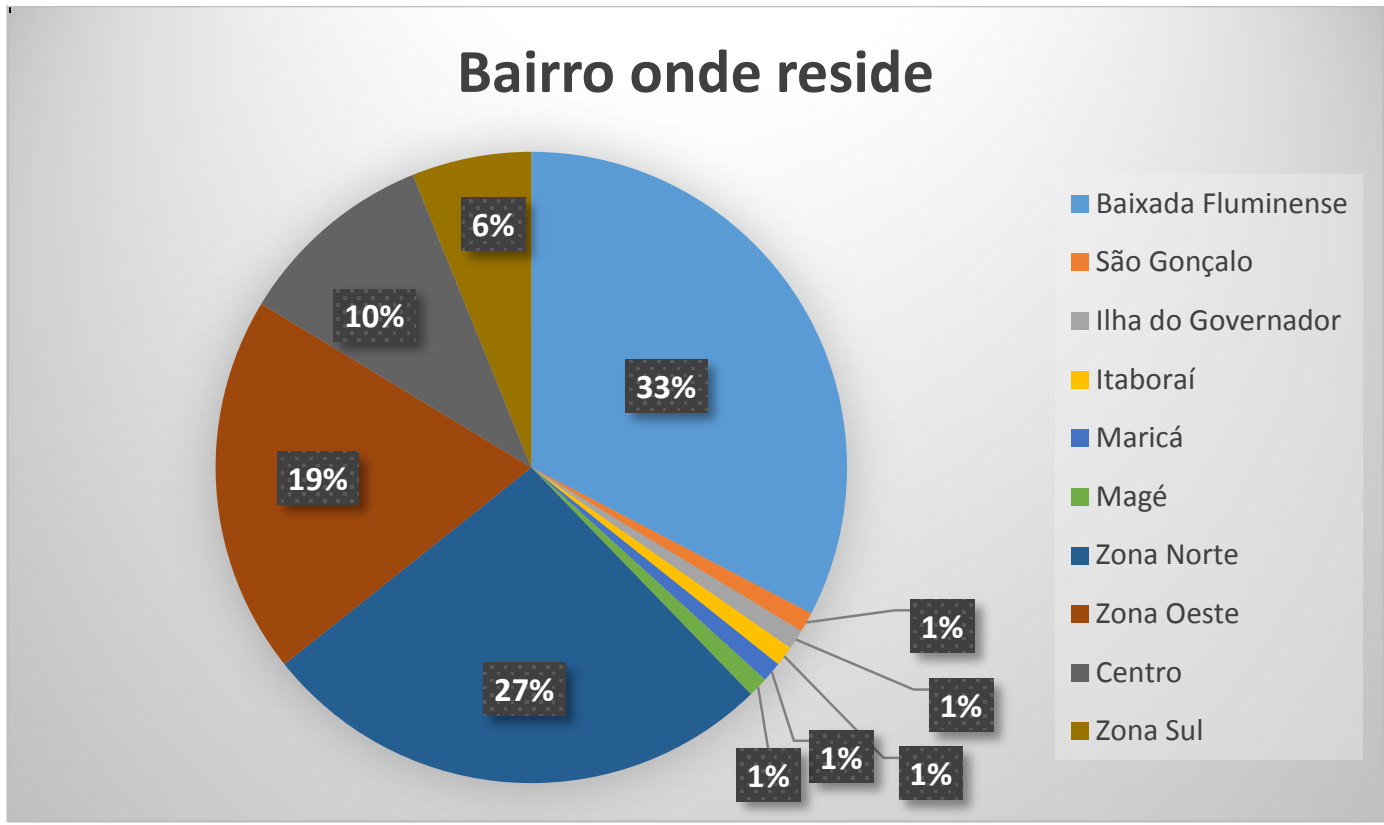

Fonte: Elaborado pelo autor a partir da ferramenta "Google Forms"

Questão 2: Qual o envolvimento e o comprometimento que os consumidores possuem para ao ir a uma oficina mecânica?

A fim de investigar o envolvimento e o comprometimento dos consumidores em relação a levar o veículo para uma oficina de reparação, foi questionado a eles a frequência com que consomem esse tipo de serviço e os 
atributos dos serviços cujos consumidores consideram favoráveis e prejudiciais para levar seu veículo à uma determinada oficina em detrimento à outra. Os dados obtidos são apresentados a seguir:

Gráfico 8 - Frequência de presença nas oficinas mecânicas

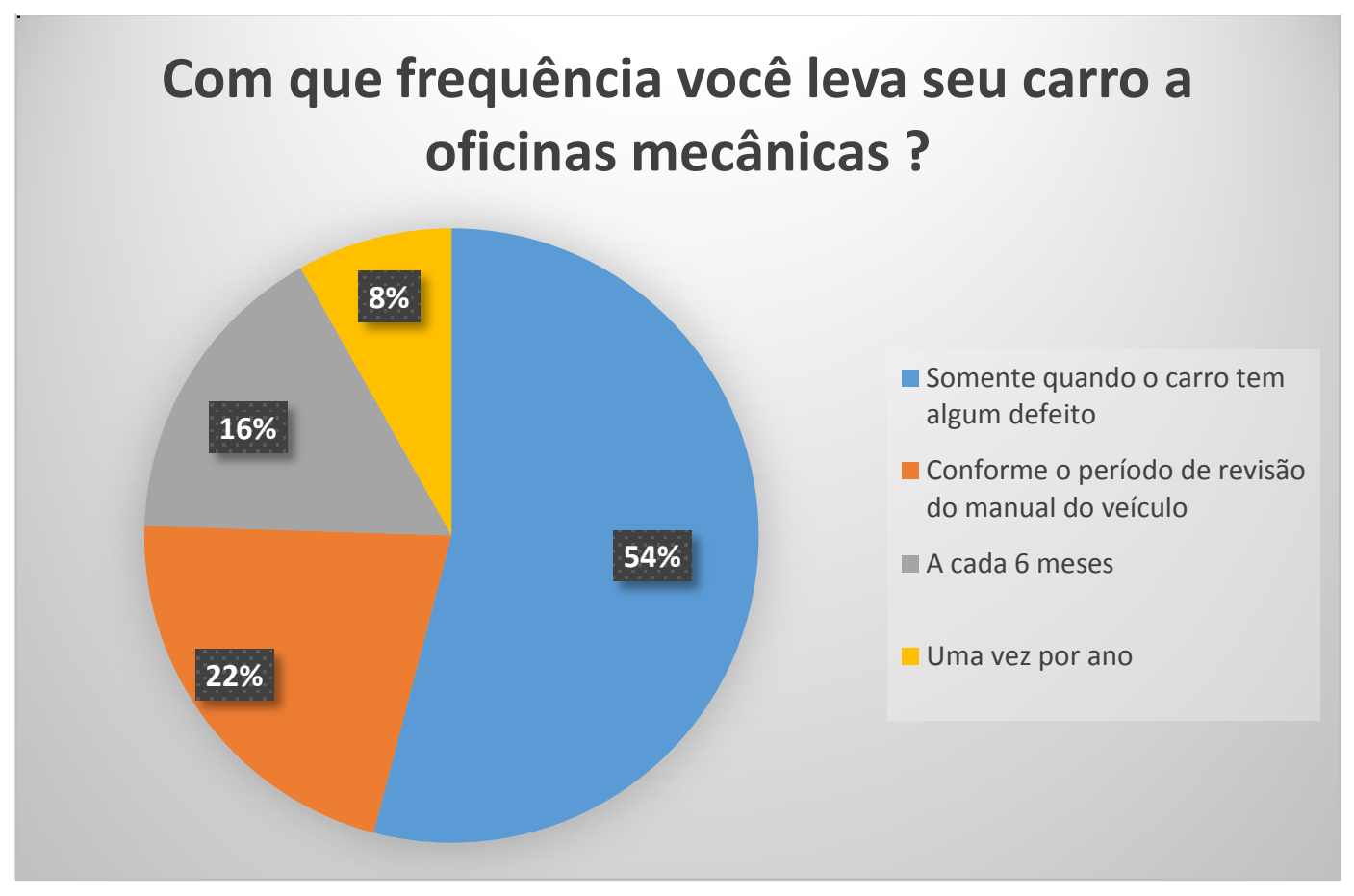

Fonte: Elaborado pelo autor a partir da ferramenta "Google Forms"

Gráfico 9 - Atributos que são diferencias na escolha de uma oficina

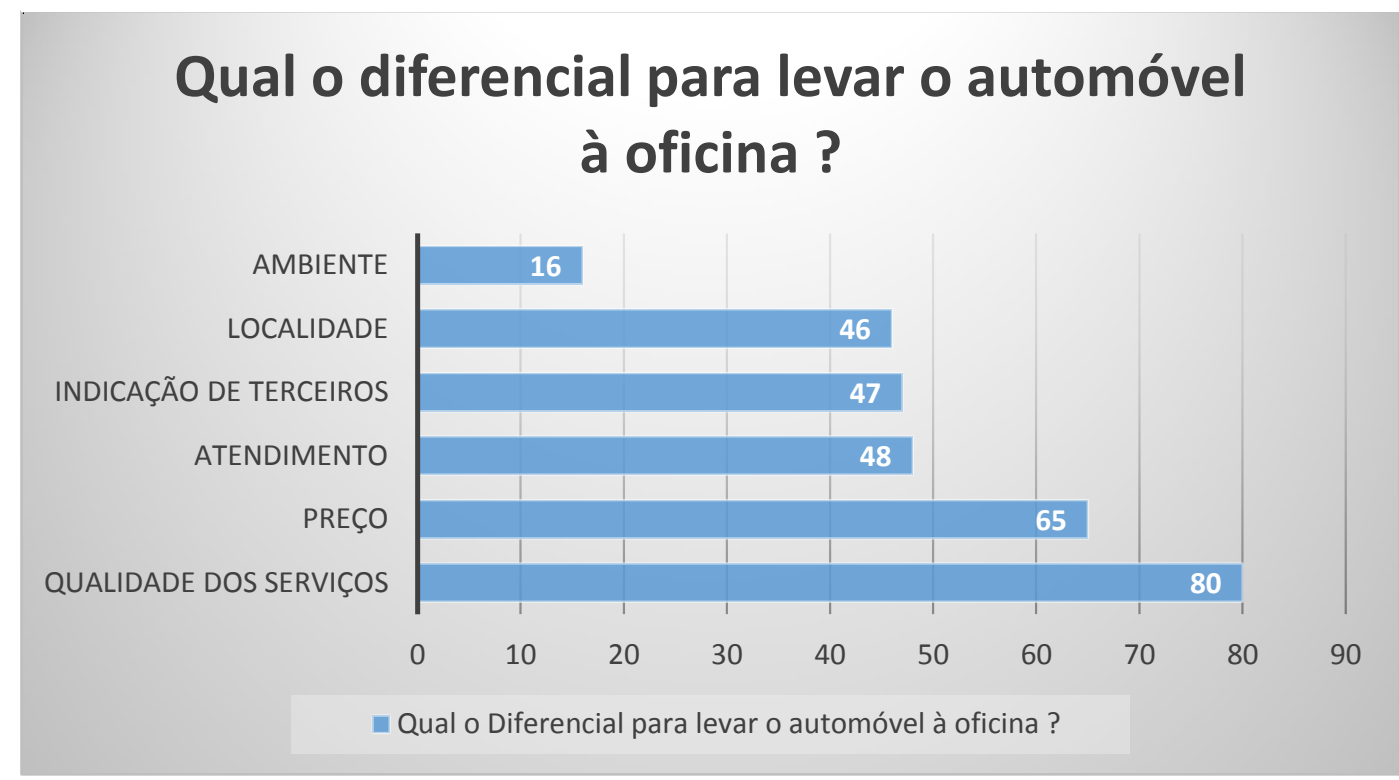

Fonte: Elaborado pelo autor a partir da ferramenta "Google Forms" 
Gráfico 10 - Atributos que causam prejuízo na escolha de uma oficina

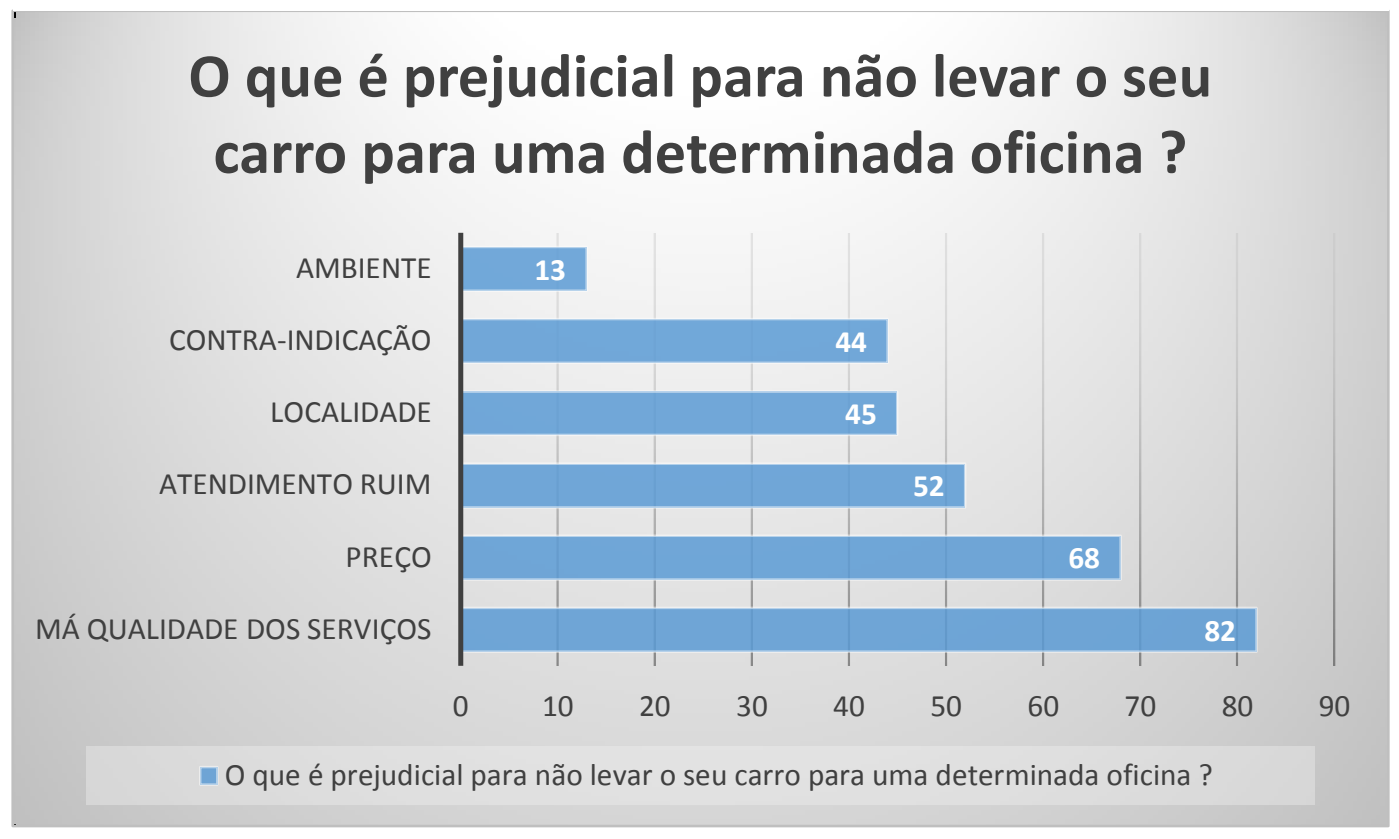

Fonte: Elaborado pelo autor a partir da ferramenta "Google Forms"

Questão 3: O que faz os consumidores terem uma preferência entre oficinas mecânicas concorrentes? Qual a percepção dos consumidores em relação à qualidade e à confiabilidade dos serviços de um tipo de oficina em detrimento de outra?

Para colher informações relevantes sobre tal aspecto, foram apresentados 4 tipos de oficinas que se diferenciam, basicamente, em seu porte estrutural. São elas:

1. Car Service com Marca: Oficina de grande porte vinculada à uma grande marca de serviços automotivos com gama variada de serviços, muitos funcionários e ampla infraestrutura (3 ou mais elevadores).

Figura 3 - Car Service com marca (imagem ilustrativa)

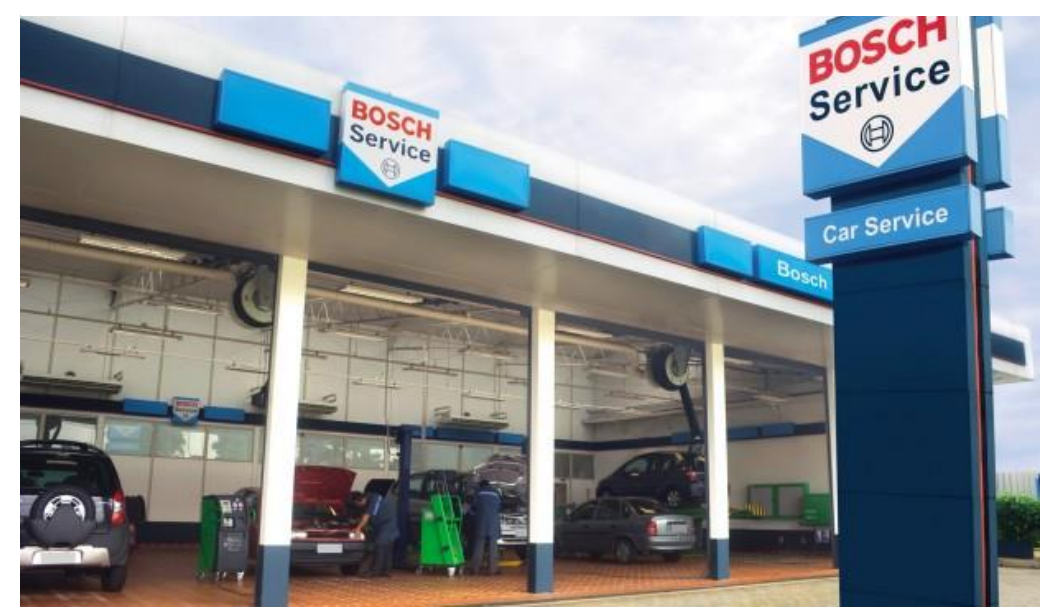


Fonte: Housepress.com.br (2014)

2. Car Service sem marca ou de marca própria: Oficina de grande ou médio porte de marca própria ou sem marca atribuída com gama variada de serviços e infraestrutura média (2 elevadores).

Figura 4 - Car Service sem marca ou de marca própria (imagem ilustrativa)

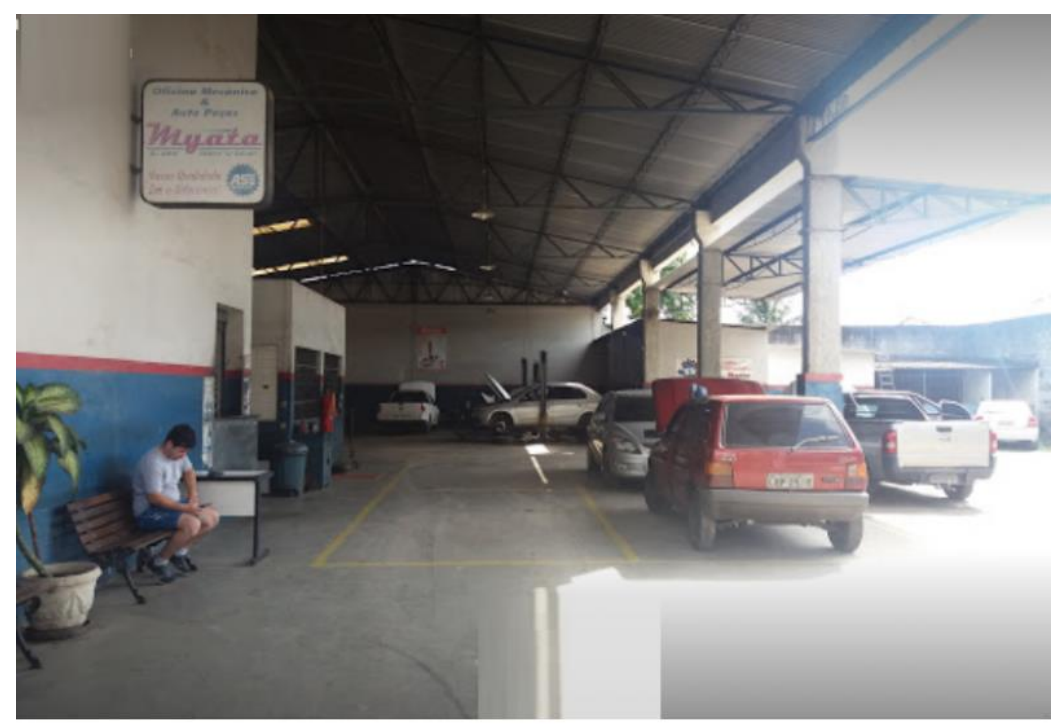

Fonte: anuncioemfoco.com.br (2018)

3. Oficina de pequeno porte: Oficina com infraestrutura limitada (1 elevador), poucos funcionários e pouca variedade de serviços.

Figura 5 - Oficina de pequeno porte (imagem ilustrativa)

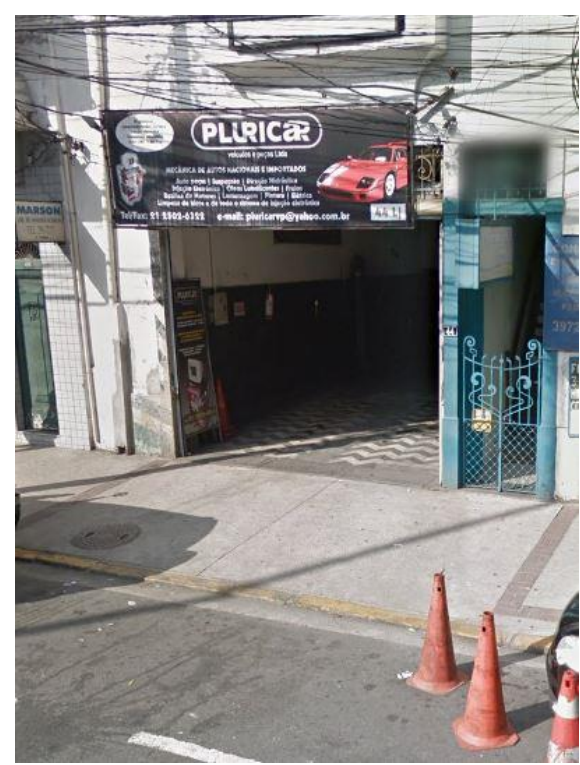


Fonte: Googlemaps.com (2018)

4. Oficina independente: Oficina geralmente com poucos equipamentos, infraestrutura muito limitada (nenhum elevador), geralmente com um profissional responsável por todo o processo de prestação de serviço (atendimento, reparação, pós-venda) e com pouca variedade de serviços.

Figura 6 - Oficina independente (imagem ilustrativa)

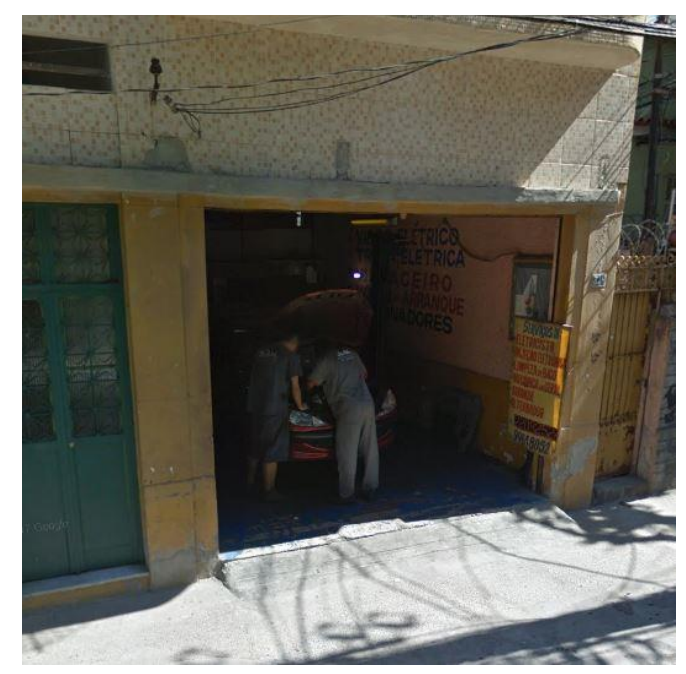

Fonte: googlemaps.com (2018)

Levando-se em consideração as oficinas propostas, foram investigados, com base na percepção e experiências prévias dos respondentes, quais oficinas tem preferência na escolha para reparar o veículo, qual oficina presta o melhor atendimento e qual são a mais qualificada para reparar veículos e os principais motivos de escolha citados pelos respondentes, conforme os resultados apresentados a seguir:

Gráfico 11 - Preferencia de escolha de oficinas

\section{Qual das oficinas citadas você levaria seu carro para revisão?}


Fonte: Elaborado pelo autor a partir da ferramenta "Google Forms"

Tabela 1 - Principias motivos de escolha de oficina

\begin{tabular}{|c|c|}
\hline \multicolumn{2}{|c|}{ Principais motivos de escolha de oficina } \\
\hline Menor Preço & Segurança \\
\hline Indicação & Variedade de serviços \\
\hline Qualidade com preço justo & Confiabilidade \\
\hline Atendimento direto e pessoal & Maior precisão do diagnóstico \\
\hline
\end{tabular}

Fonte: Elaborado pelo autor a partir da ferramenta "Google Forms"

Gráfico 12 - Opinião sobre o atendimento das oficinas

\section{Qual das oficinas prestaria o melhor atendimento?}

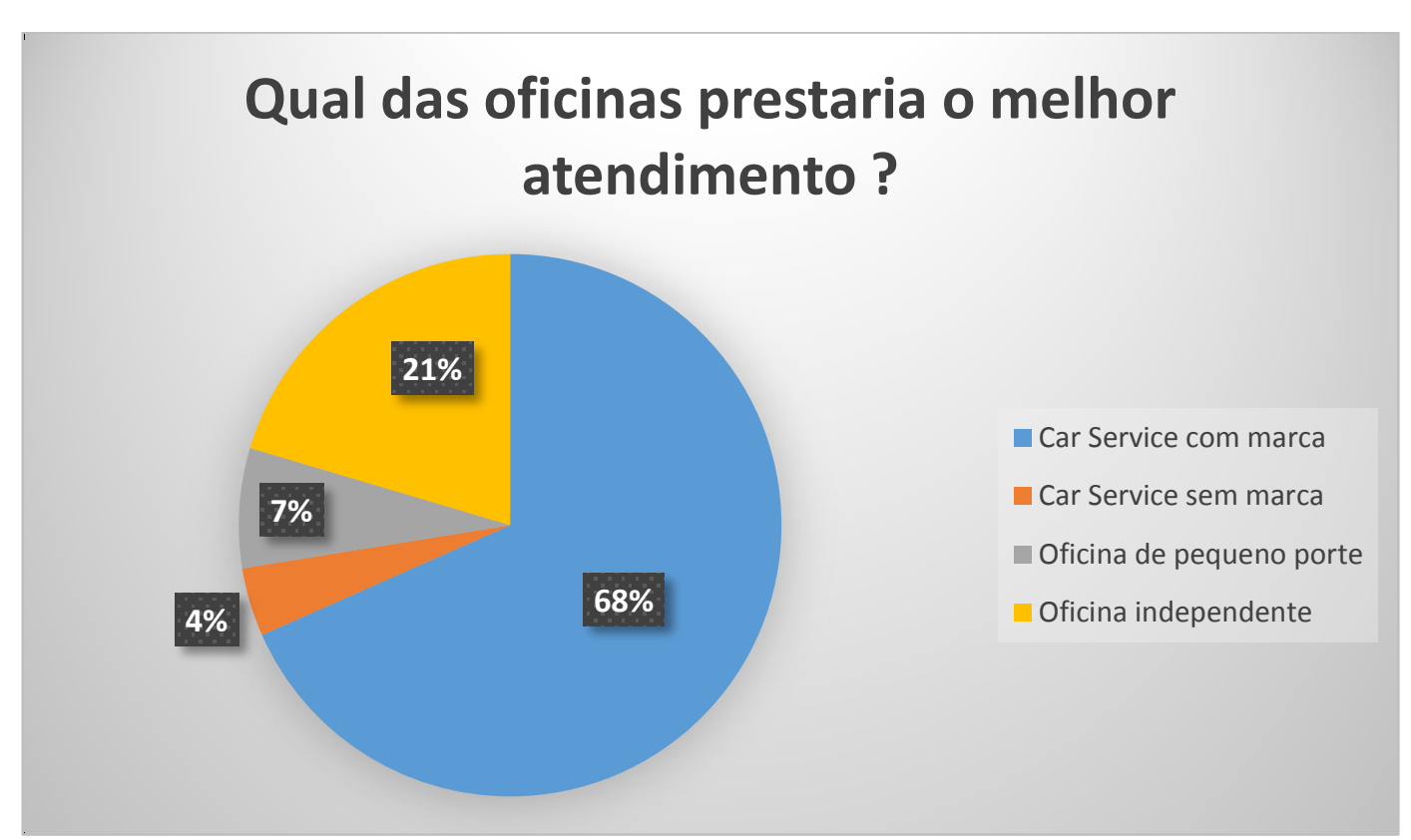

Fonte: Elaborado pelo autor a partir da ferramenta "Google Forms"

Tabela 2 - Principais motivos de escolha - Atendimento

\begin{tabular}{|c|c|}
\hline \multicolumn{2}{|c|}{ Principais motivos para escolha - Atendimento } \\
\hline Mais caro, atendimento melhor & Suporte técnico \\
\hline Acompanhamento do serviço & Controle de qualidade \\
\hline Melhor infraestrutura & Confiança aliada a preço \\
\hline
\end{tabular}




\begin{tabular}{|c|c|}
\hline Melhor atendimento & Investimento da marca \\
\hline
\end{tabular}

Fonte: Elaborado pelo autor a partir da ferramenta "Google Forms"

Gráfico 13 - Opinião sobre qualificação das oficinas

\section{Qual dessas oficinas tem mais qualificação para reparar o seu carro?}

$16 \%$

$5 \%$

$7 \%$

$72 \%$
- Car Service com marca

- Car Service sem marca

- Oficina de pequeno porte

Oficina independente

Fonte: Elaborado pelo autor a partir da ferramenta "Google Forms"

Tabela 3 - Principais motivos de escolha - Qualificação

\begin{tabular}{|c|c|}
\hline \multicolumn{2}{|c|}{ Principais motivos de escolha - Qualificação } \\
\hline $\begin{array}{c}\text { Oficinas grandes tem melhores } \\
\text { mecânicos }\end{array}$ & Oficinas maiores tem mais variedade \\
de serviços
\end{tabular}

Fonte: Elaborado pelo autor através da ferramenta "Google forms"

A fim de analisar o grau de satisfação dos clientes, foi utilizada a teoria do Net Promoter Score (NPS) que consiste em uma métrica utilizada para avaliar a experiência de compra do cliente e cujo objetivo é medir a satisfação e a lealdade dos clientes (RAMPINELLI, 2014). O método do NPS consiste em classificar as respostas dos clientes em três categorias: 
1. Clientes Detratores (notas de 0 a 6): Clientes totalmente insatisfeitos com os serviços prestados.

2. Clientes Neutros (notas 7 e 8): Clientes não leais que compram quando tem necessidade. Se a concorrência oferecer um benefício que sua empresa não fornece, este optará pela troca da concorrência.

3. Clientes Promotores (notas 9 e 10): São clientes que possuem um relacionamento de afeto com a marca. Estão muito satisfeitos com a aquisição dos serviços, são leais, oferecem feedbacks positivos e ajudam no crescimento da empresa.

Segundo Rampinelli (2014) a forma de calcular o NPS consiste na seguinte equação:

Imagem 7: Fórmula do Net Promoter Score (NPS)

\section{Net Promoter Score $=\%$ Promoters $\quad-\quad \%$ Detractors}

Fonte: dds.com.br (2014)

Com base na definição, os resultados do Net Promoter Score (NPS) de cada oficina citada anteriormente com base nas informações colhidas na amostra são:

Gráfico 14 - NPS - Car Service com marca

\section{Car Service com marca}

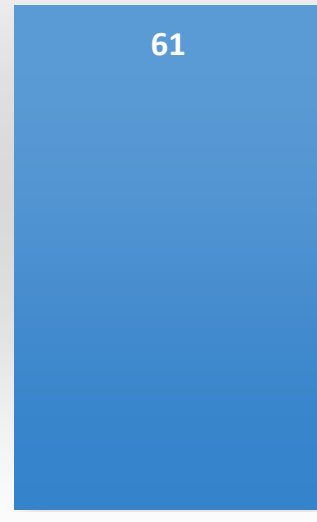

Promotores

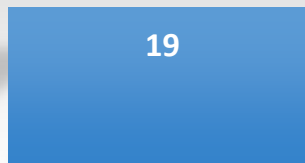

Neutros

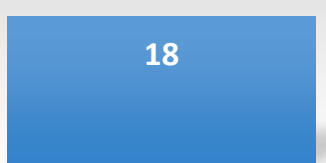

Detratores 
Fonte: Elaborado pelo autor com base na ferramenta "Google forms".

Gráfico 15 - NPS - Car Service sem marca

\section{Car Service sem marca}

$N P S=21-45->N P S=-24$

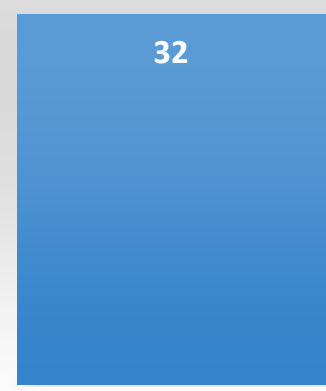

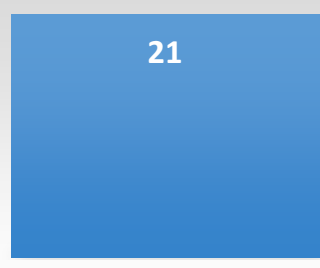

Promotores
45

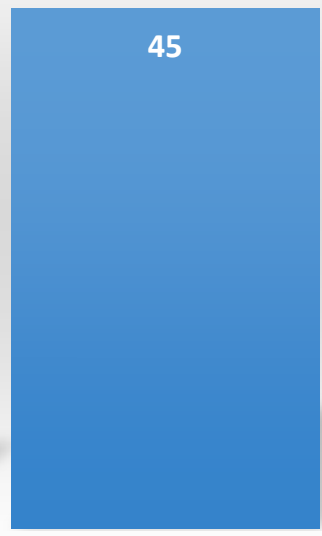

Detratores

Fonte: Elaborado pelo autor a partir da ferramenta "Google Forms"

Gráfico 16 - NPS - Oficina pequeno porte

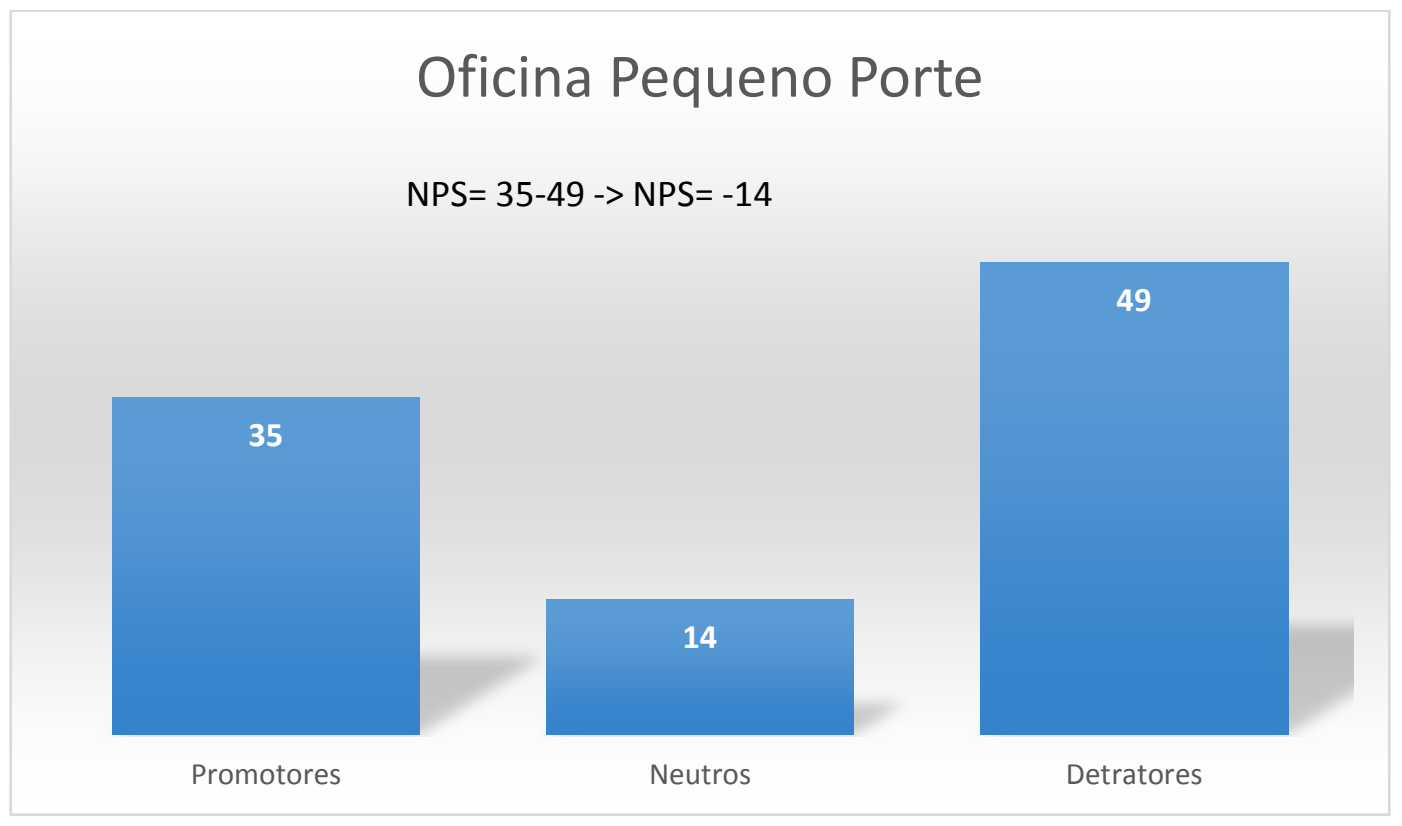

Fonte: Elaborado pelo autor a partir da ferramenta "Google Forms". 
Gráfico 17 - NPS - Oficina Independente

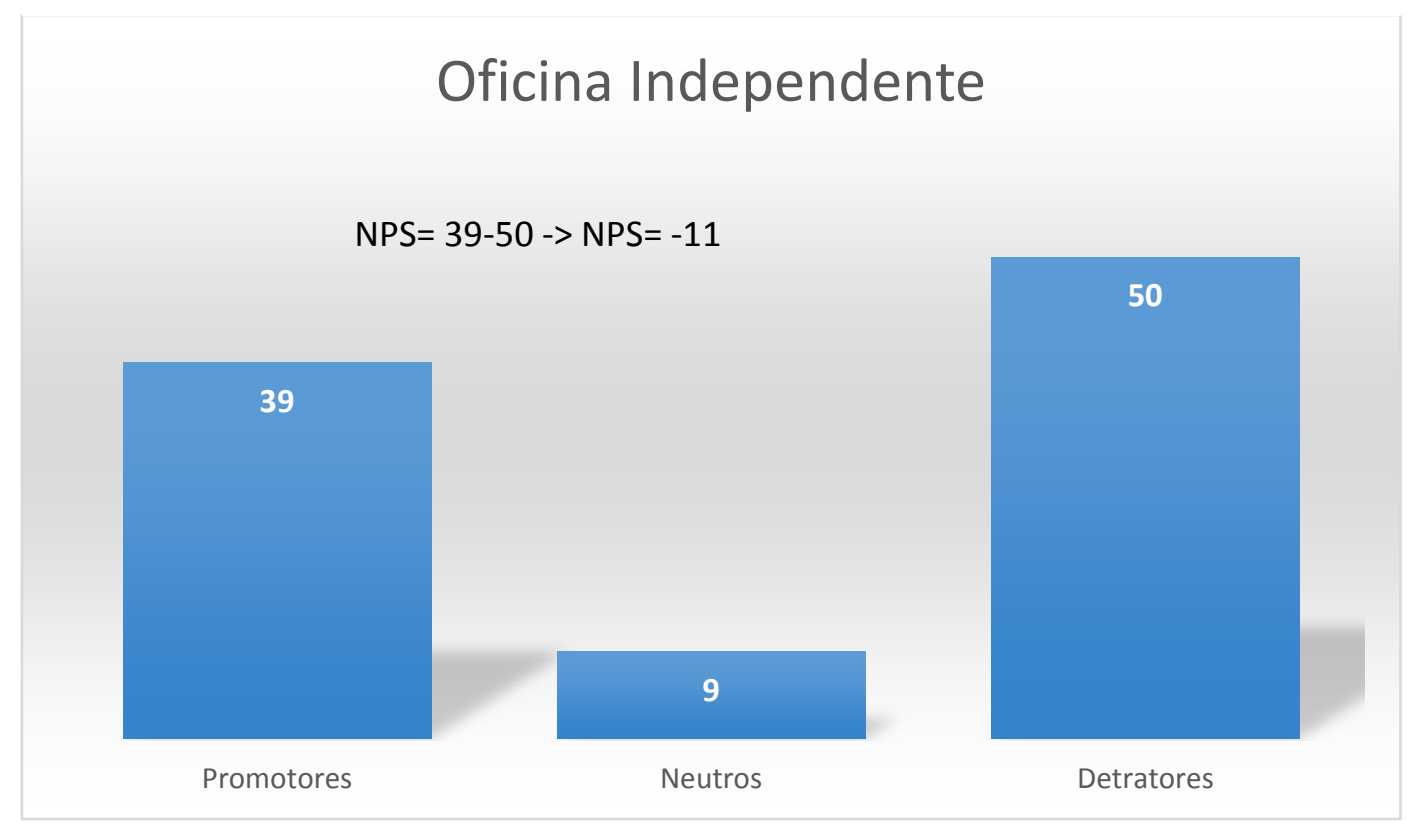

Fonte: Elaborado pelo autor a partir da ferramenta "Google Forms".

\subsection{Análise final dos resultados}

Após a descrição dos resultados, será feita a análise dos resultados obtidos da amostra, com base nas questões que pautaram a pesquisa.

Questão 1: Quais são as características demográficas da amostra?

Nota-se, conforme o gráfico 3, que há uma maior concentração do público masculino que possui veículo próprio e possui experiência em adquirir serviços de reparação em oficinas mecânicas. Assédio, ambiente insalubre e intimidador e a desonestidade de alguns profissionais faz com que o público feminino delegue essa função para um companheiro ou algum parente, por ter receio de ter seus direitos violados e este pode ser um fator determinante para a baixa quantidade de respondentes femininas na amostra.

Outro aspecto que vale ressaltar é a média da renda dos respondentes, em que mais da metade (51\%) declara ganhar até dois salários mínimos (até R\$1874) 
conforme é observado no gráfico 4. Este fato evidencia um traço cultural carioca de que se busca uma solução de qualidade para o problema, pagando-se o mínimo possível.

A localidade onde reside o respondente é outro fato importante a se analisar, uma vez que pode existir uma concentração de um determinado tipo de oficina citada no estudo, maior em determinada região, assim gerando poucas opções de escolha e variedade de fornecimento dos serviços de reparação e o comportamento de compra dos respondentes de determinada região é diferente das demais regiões, que buscam outros atributos para consumir estes serviços.

O grau de escolaridade e a idade dos respondentes são aspectos analisados, pois, influenciam no processo de compra devido ao grau de instrução do consumidor e das experiências vividas com um ou mais tipos de oficinas citadas neste estudo.

Questão 2: Qual o envolvimento e o comprometimento que os consumidores possuem para ao ir à uma oficina mecânica?

É possível notar ao analisarmos os dados mostrados no gráfico 8 outro traço cultural do público carioca: a ausência de planejamento e comprometimento dos consumidores com o prazo de reparação do veículo. Um automóvel consiste de uma engenharia avançada agregada a muitos componentes que, com o tempo e o tipo de uso do veículo, tendem a ter desgastes e os prazos de revisões de tais componentes devem ser respeitados para um melhor funcionamento e segurança no transito.

Dentro desta questão, um aspecto interessante que novamente ressalta a forte característica cultural carioca em relação à reparação de autos é a determinação de atributos que fazem a diferença no momento de escolha de uma oficina em detrimento das concorrentes. Preço e qualidade dos serviços são os atributos que fazem a diferença tanto positivamente quanto negativamente para os consumidores na hora de decidir em qual oficina irão reparar o seu veículo, seguidos de atendimento, localidade e indicação, que foram outros atributos considerados relevantes, porém, em menor magnitude se comparados a preço e qualidade. 
Questão 3: O que faz os consumidores terem uma preferência entre oficinas mecânicas concorrentes? Qual a percepção dos consumidores em relação à qualidade e à confiabilidade dos serviços de um tipo de oficina em detrimento de outra?

Nesta questão, mais uma vez, foi evidenciado o forte traço cultural do carioca ao se analisar os resultados presentes no gráfico 11, de qual oficina os respondentes têm preferência para levar o veículo para revisão; nota-se que há uma preferência pela oficina independente, devido a esta possuir o maior potencial de aliar um preço menor a uma boa qualidade nos serviços e confiabilidade. Além destes atributos citados, outros atributos que evidenciam a escolha dos respondentes estão presentes na tabela 1, como o atendimento pessoal, indicação e precisão no diagnóstico.

Ao se avaliar a opinião dos respondentes sobre qual tipo de oficina possui melhor atendimento e alta qualidade na prestação de serviços (gráficos 12 e 13) se obtiveram resultados semelhantes, em que prevaleceu a opinião de que a oficina com maior infraestrutura e investimento de marca tem mais qualidade na prestação de serviços e no atendimento ao consumidor. Outro fator importante a se frisar nestes resultados é a alta associação da qualidade dos serviços e bom atendimento com um preço mais elevado dos serviços. Outros atributos mencionados como motivos para escolha da oficina Car Service com marca como uma oficina que oferece suporte técnico, melhor infraestrutura, investimento em capacitação e controle de qualidade estão presentes nas tabelas 2 e 3. Os dados obtidos relativos ao Net Promoter Score (NPS) de cada tipo de oficina considerada no estudo, serão avaliados com base em 4 classificações (RAMPINELLI, 2014):

1. Zona de Excelência: pontuação entre 75 e 100 - Empresas que atingem esta pontuação geraram grandes experiências e agregam valor para os seus clientes.

2. Zona de Qualidade: pontuação entre 50 e 74 - Os clientes desta faixa de avaliação observaram diversos pontos positivos durante a experiência com a empresa, porém alguns pontos deixaram a desejar. 
3. Zona de Aperfeiçoamento: pontuação entre 0 e 49 - A experiência oferecida nesta faixa de NPS tem pontos importantes de ajustes pois, em muitos casos, o cliente não percebeu atenção com o seu caso ou sua necessidade.

4. Zona Crítica: pontuação entre -100 e -1 - A experiência foi altamente frustrante para o consumidor e ele será o primeiro a reclamar e denegrir a imagem da empresa com outras pessoas.

Segundos os cálculos do NPS efetuados nos gráficos 14 a 17, observa-se que apenas a Car Service com marca possui NPS positivo mas encontra-se na zona de aperfeiçoamento, ou seja, ainda possui pontos a serem melhorados para que os consumidores cariocas se sintam mais satisfeitos com os serviços prestados. Em contrapartida, a Car Service sem marca ou de marca própria, a oficina de pequeno porte e a oficina independente encontram-se na zona crítica, onde existem muitos pontos a serem melhorados para proporcionar uma experiência de consumo melhor para os consumidores cariocas. 


\section{Considerações Finais}

O objetivo final deste estudo foi averiguar a percepção e as atitudes dos consumidores cariocas em relação aos serviços prestados por oficinas mecânicas de automóveis independentes e especializadas da região metropolitana do estado do Rio de Janeiro.

É notório que as características culturais do carioca são bastante peculiares e influenciam diretamente no processo de compra desses tipos de serviços, pois não há um alto nível de envolvimento do carioca tanto com seu próprio bem (automóvel) quanto com o processo de compra. A prática do zelo dos cariocas com seus veículos é muito baixa e isto compromete a segurança do trânsito e diminui a qualidade dos serviços de reparação pois, no momento de tomar uma decisão de escolha sobre o tipo de oficina ideal para levar o veículo para uma revisão ou reparação, é reconhecido pelos cariocas que as oficinas especializadas possuem melhor infraestrutura para atender e prestar um serviço com mais qualidade, porém, há uma tendência destes abdicarem desses atributos em troca de uma solução mais barata sem que haja uma perda drástica de qualidade, dentro das possibilidades.

Existem inúmeras melhorias a serem feitas no ramo da reparação automotiva como uma melhor capacitação dos profissionais do ramo e acessibilidade de equipamentos a fim de melhorar a infraestrutura das oficinas, por exemplo, são aperfeiçoamentos que devem ser considerados a fim de promover um aumento global do Net Promoter Score (NPS) das oficinas citadas no estudo.

Existem também algumas oportunidades de mercado que podemos deduzir por meio dos resultados obtidos na presente pesquisa, como um atendimento mais amigável para com o público feminino que, por sua vez, tem representatividade em ascensão no mercado de trabalho e um poder aquisitivo também em ascensão, sendo um público muito pouco explorado pelo mercado. Outra oportunidade de mercado é o público que possui automóveis clássicos, haja vista que os proprietários de tais automóveis têm dificuldade de encontrar mão de obra adequada para reparação e/ou restauração dos mesmos. 
Com o avanço da tecnologia, o mercado automobilístico vem se reinventando e renovando e existem tendências que influenciam diretamente no mercado de reparação que são os veículos autônomos (automóveis planejados para trafegarem sem motorista), automóveis criados para consumir combustíveis de fontes renováveis (biocombustível, etanol) e carros com sistemas de propulsão alternativos (elétrico, células de combustível, hidrogênio, híbridos) são tendências do setor que irão demandar capacitação de mão de obra para reparo e melhorias na infraestrutura e ferramental das oficinas. 


\section{Referências Bibliográficas}

ANÁLISE do mercado de reposição: dados oficiais em contraponto com desempenho das oficinas. Jornal Oficina Brasil. Disponível em: http://www.oficinabrasil.com.br/noticia/mercado-cinau/analise-do-mercado-de reposicao-dados-oficiais-em-contraponto-com-desempenho-das-oficinas. Acesso em: 19 jun. 2017.

A IMPORTÂNCIA do setor terciário. Ministério da Indústria, Comércio Exterior e Serviços. Disponível em: http://www.mdic.gov.br/index.php/comercio-servicos/a-secretaria-de-comercio-eservicos-scs/402-a-importancia-do-setor-terciario. Acesso em: 24 mai. 2018

BABBIE, E.R. The basics of social research. 5 ed. California: Wadsworth Publishing Company, 2011.

CAMARGO, Camila; KEISER, Juliana I. Uma Análise das Intersecções entre Finanças Pessoais, Finanças Organizacionais e Desempenho no Pequeno Varejo. Disponível em: http://www.anpad.org.br/admin/pdf/ESOC2936.pdf. Acesso em: 02 mai. 2018

CHURCHILL, Gilbert. Marketing research: methodological foundations. 2a ed. Forth Worth:The Dryden Press. 1998.

CRESWELL, J. W. Projeto de Pesquisa: Métodos qualitativo, quantitativo e misto. $2^{\mathrm{a}}$ Ed. Porto Alegre: Artmed Editora, 2007.

ELIAS, Rodrigo Vilela; MOURÃO, Ludmila. Automobilismo carioca: memórias de um piloto e as corridas de rua de 1954 a 1966. Disponivel em: http://seer.ufrgs.br/index.php/Movimento/article/view/9778. Acesso em: 27 mai. 2018

FONSECA, João José Saraiva da. Metodologia da pesquisa científica. Ceará: Universidade Estadual do Ceará, 2002.

GIL, Antonio Carlos. Métodos e técnicas de pesquisa social. São Paulo: Atlas, 1987.

GRÖNROOS, Christian. Marketing: Gerenciamento e Serviços. $2^{\mathrm{a}}$ ed. Rio de Janeiro: Campus, 2004.

KINNEAR, Thomas C.; TAYLOR, James R. Marketing research: an applied aproach. New York: Mc Graw Hill. 1979.

KOTLER, Philip. Administração de marketing: análise, planejamento, implementação e controle. 5. ed. São Paulo: Atlas, 1998.

KOTLER, Philip; KELLER, Kevin Lane. Administração de Marketing. $12^{\mathrm{a}}$ Ed. São Paulo: Pearson, 2006. 
MYATA Car Service. Anuncio em foco. Disponível em: http://www.anuncioemfoco.com.br/oficina-mecanica-santa-cruz-rj. Acesso em 27. Abr. 2018

O CIRCUITO da Gávea. Histórias do Sport. Disponivel em: https://historiadoesporte.wordpress.com/2013/09/09/o-circuito-da-gavea/. Acesso em: 27 mai. 2018

PERIARD, Gustavo. Tudo sobre a Teoria dos Dois Fatores de Frederick Herzberg. Disponível em: http://www.sobreadministracao.com/tudo-sobre-ateoria-dos-dois-fatores-de-frederick-herzberg/. Acesso em: 20 jun. 2017

RAMPINELLI, Felipe. Tudo sobre NPS: Como calcular, classificações e vantagens. Disponível em: https://www.dds.com.br/blog/index.php/entendaimportancia-nps-para-sua-empresa/. Acesso em: 1 jun. 2018

REDE Bosh Car Service lança promoção "Viva o Momento". Housepress. Disponível em: http://www.housepress.com.br/index.php/rede-bosch-car-servicelanca-promocao-viva-o-momento/. Acesso em: 27 abr. 2018

RICHARDSON, R.J. Pesquisa Social: métodos e técnicas. 3 ed. São Paulo: Atlas, 1999.

SANTOS, José Luiz dos. O que é cultura? Rio de Janeiro: Brasiliense, 1994.

SAUNDERS, M.; LEWIS, P.; THORNHILL, A. Research Methods for Business Students. Harlow:Prentice Hall, 2001.

SILVA, Liliam Maria. Crença, atitude e comportamento. Disponível em: http://www2.anhembi.br/html/ead01/comportamento_consumidor/pdf/aula_04.pdf . Acesso em: 27 mai.2018

SCHIFFMAN, L. G.; KANUK, L. L. Comportamento do Consumidor. Rio de Janeiro: LTC Editora. 2000.

SHETH, J. N.; MITTAL, B.; NEWMAN. B. I. Comportamento do cliente: indo além do comportamento do consumidor. São Paulo: Atlas, 2001.

SOLOMON, M. R. O comportamento do consumidor: comprando, possuindo e sendo. Trad. Lene Belon Ribeiro. 5. ed. Porto Alegre: Bookman, 2008 . 